\title{
A feature model of immediate memory
}

\author{
JAMES S. NAIRNE \\ Purdue University, West Lafayette, Indiana
}

\begin{abstract}
A feature model of immediate memory is presented, and simulations are described. List items are characterized as multiattribute vectors that can be selectively overwritten by subsequent external events and by the ongoing stream of internal activity. Degraded primary memory vectors are compared with intact secondary memory vectors, and retrieval likelihood is computed as the ratio of similarities. The model is shown to account for the major modality-based phenomena of the immediate serial recall literature, including modality-based temporal grouping effects and the negative effects of phonological similarity.
\end{abstract}

The ability to reconstruct recently presented information as it recedes backward in time is basic to a fully functioning cognitive system. The interpretation of spoken language, among other examples, requires the preservation of temporal order information, a task that is typically assumed to be a critical function of primary, or short-term, memory. This article describes a simulation model that handles a variety of phenomena characteristic of immediate retention. The model is based on an earlier descriptive framework (Nairne, 1988); its main appeal is to the composition of list traces in primary memory and to the manner in which trace composition might change as a function of interference from externally presented events and ongoing cognitive activities. The focus of the simulation studies is on modality-based effects in immediate memory. These effects are quite large and stable empirically, and their analysis exploits the feature-based properties of the model. In a later section, I apply the proposed mechanics to a range of other benchmark data in the immediate memory literature.

Of the many variables that can affect performance in a task such as immediate serial recall, where subjects are required to reproduce short lists of items in the exact order of presentation, one of the more conspicuous is presentation modality. The modality effect refers to the superior recency performance that occurs for auditory, compared with visual, presentation. Typically, serial recall of auditory and visual lists leads to declining performance over serial position, but, for the last few serial positions, there is a relative auditory advantage (Conrad \& Hull, 1968; Corballis, 1966; Craik, 1969; Murdock \& Walker, 1969; Murray, 1966). The stimulus suffix effect is a related phenomenon, which is observed when an extra item, usually a word presented aloud, eliminates the modality

Nader Amir made valuable contributions to the simulations reported here. Thanks are also due to I. H. Bernstein, R. G. Crowder, J. R. Erickson, R. L. Greene, B. B. Murdock, Jr., C. G. Penney, and M. J. Watkins for their comments on an earlier version of the manuscript. Correspondence concerning this article may be addressed to James S. Nairne, Department of Psychological Sciences, Purdue University, West Lafayette, IN 47907. effect by reducing the recency advantage that is found for auditory lists (Dallett, 1965).

The presentation of list information aloud also interacts significantly with the organization of presentation: If a nine-item list is presented with the items in groups of three, separated by short pauses, auditory presentation leads to large grouping advantages, relative to visual presentation, and, within each group, there is a recency advantage for the last serial position (Frankish, 1985, 1989; Ryan, 1969). In addition, under auditory presentation, increasing the phonological similarity among the items in a list produces performance decrements in recall, even in the presence of continued articulatory suppression (repeating a constant throughout list presentation); with visual presentation, the suppression of articulation has been shown to eliminate phonologically based differences in recall (Estes, 1973; Levy, 1971; Peterson \& Johnson, 1971).

In the sections that follow, I describe the assumptions of the model in some detail and present the results of a number of simulation studies. A simple version of the model is shown to deal effectively with a number of basic modality-related effects, thereby tying the phenomena together within a common framework. The discussions also point out ways in which the simple model is incomplete, and suggestions are made about alternative conceptions. In the final section, I compare the feature model with past attempts to describe modality-dependent serial recall performance in an effort to trace its intellectual lineage and to argue for its advantages.

\section{DESCRIPTION OF THE FEATURE MODEL}

There are a number of similarities between the present approach and other general memory models, and these commonalities are worth noting briefly. First, a distinction is drawn between primary and secondary memory (James, 1890): primary memory traces are active representations in memory, subject to degrading through interference; secondary memory is conceived as the more permanent repository of experience. Primary memory is argued to contain a kind of real-time record of temporal order information, and analysis of its traces is assumed 
to form the basis for performance in immediate memory tasks. Second, memory traces are represented in primary and secondary memory as vectors, or lists of features that can differ in value and type; the psychological reality, as well as the computational benefits, of this kind of representational system have been discussed by others (e.g., Bower, 1967; Eich, 1982; Estes, 1980; Hintzman, 1986; Murdock, 1983).

Third, immediate recall is based on a comprehensive matching process in which residual trace information in primary memory is compared to groups of relevant traces in secondary memory; the latter traces define a secondary memory search set (Eich, 1982; Gillund \& Shiffrin, 1984; Hintzman, 1986; Raaijmakers \& Shiffrin, 1981; Ratcliff \& McKoon, 1988). In the present case, the basis for the comparison process is trace similarity, which is measured by the amount of feature overlap between compared vectors (Hintzman, 1986; Nosofsky, 1986). Finally, and importantly, the to-be-recalled items are selected from the search set according to a choice or ratio rule (Gillund \& Shiffrin, 1984; Glenberg \& Swanson, 1986; Luce, 1963; Nosofsky, 1986; Raaijmakers \& Shiffrin, 1981). Such a rule provides for an explicit treatment of trace distinctiveness; its use, as others have shown, allow one to make a range of predictions outside of the restricted topic of immediate serial recall (see, in particular, Nosofsky, 1986; Raaijmakers \& Shiffrin, 1981).

\section{The Composition of Traces}

List items are represented as vectors, containing features that can vary in qualitative type, quantitative value, and number. An item's physical features are referred to as modality-dependent, because differences in the composition of memory traces as a function of the modality of presentation are of primary interest. In a more general sense, modality-dependent features are meant to represent the presentation conditions and likely consist of both intraitem (e.g., modality, language, distinctive features of the type specified by Jakobson, Fant, \& Halle, 1951, typeface, etc.) and extra-item (e.g., room cues, etc.) contextual attributes (Bjork \& Richardson-Klavehn, 1989; Geiselman \& Bjork, 1980).

Each list item is encoded simultaneously into primary and secondary memory, with probability $L$, and the result is a complex multiattribute memory trace consisting of the encoded list features and an additional set of internally generated modality-independent features. The latter features accrue from the processes of categorization and comprise an inner voice label of identification for the presented list item. It is assumed that modalityindependent features are usually represented in the form of a phonological code (Conrad, 1964), but other representational formats are certainly possible (e.g., semantic or imaginal; see Shulman, 1972).

The modality-independent features of a trace, at least in the majority of instances, are derived from a global categorization process and do not depend intimately on the modality of presentation; thus, auditory or visual pre- sentation of a particular item (e.g., the digit 9) should lead to a nearly identical ensemble of modality-independent features. In the language of the sensory memory literature, these traces contain identical postcategorical features, identifying the item as a 9 , but a quite different collection of precategorical components, representing the conditions of presentation (e.g., auditory or visual). In such a case, a subject could be expected to discriminate between the auditory and visual traces only through a comparison of the modality-dependent features. At another extreme, auditory presentation of homophones (pear, pair, pare) leads to traces with highly similar modality-dependent features, but very different modalityindependent features (provided some contextual biasing is present). The collection of physically based, modalitydependent trace features is responsible for the modalitybased recall effects of interest here.

\section{Overwriting Assumptions}

The primary mechanism of forgetting in the model is interference among contiguous traces in primary memory. The case for interference rather than decay as the operative source of forgetting has a long history and will not be detailed here (see Crowder, 1976, for a review). To many theorists, interference is the mechanism of choice because of the extensive literature implicating item similarity as a critical determinant of immediate memory performance.

An individual feature of a primary memory trace is assumed to be overwritten, with probability $F$, if that feature is matched in a subsequently occurring event. Interference occurs on a feature-by-feature basis, so that, if feature $b_{i}$ matches feature $a_{i}$, the latter will be lost with probability $F$. Modality-dependent features can only overwrite other modality-dependent features, and a similar one-to-one relationship holds for modality-independent features. Although it is assumed in the simulations that follow that overwriting leads to the permanent erasure of a feature value, the exact mechanism remains unspecified. Several studies have shown, for example, that multiple suffixes can produce less interference than can single suffixes (Crowder, 1978a; Morton, 1976; but see Watkins \& Watkins, 1982); hence, the erasure process may be complex. ${ }^{1}$

Like other memory models, dating back certainly to the early dichotomous models (e.g., Atkinson \& Shiffrin, 1971; Waugh \& Norman, 1965), it is assumed that primary memory traces can be formed through the encoding of externally presented information, such as an item on a list, or through the action of internally generated retrieval processes. Primary memory traces for list items do not exist in a "vacuum," but rather are part of a stream of representations containing many internally generated traces (see Johnson \& Raye, 1981; Nairne \& McNabb, 1985; Russo \& Wisher, 1976). In assessing a primary memory trace, the subject needs to discriminate the trace from other list traces, as well as from traces produced as by-products of the cognitive activities that occur dur- 
ing and immediately after list presentation. For example, subjects formulate strategies for retrieval, rehearse previous items, and so on, and all of these activities may potentially produce representations in primary memory.

In trace overwriting, no distinction is drawn between the interference produced by an externally based source (another list item) and the interference produced by internally generated activities. The trace for a list item is overwritten by the presentation of additional list items or by the rehearsal of previous ones. Internally generated memory traces differ from externally based traces, however, in that they contain, and can overwrite, only modality-independent features. Thus,

$$
\begin{aligned}
& \text { A : [ MI, MI, MI, MD, MD, MD ] } \\
& \mathrm{A}^{\prime}: \text { [ MI, MI, MI, 0, } 0, \quad 0 \quad \text { ] }
\end{aligned}
$$

might be the vector representations for a list item (A) and its subsequent rehearsal $\left(A^{\prime}\right)$, where $M I$ represents a modality-independent feature, $M D$ represents a modalitydependent feature, and zero stands for the absence of a feature. One implication of these representational formats for the interpretation of recency effects is that whenever list items are represented through primarily modalityindependent features, they will be especially susceptible to overwriting by internally generated traces. ${ }^{2}$ It is typically the modality-dependent (precategorical) features of a trace that make it distinctive, relative to the background activities of primary memory.

Figure 1 shows the state of affairs that might exist after the overwriting of a simple three-item list. In this case, only four trace features are depicted, taking on values of 1 or -1 , and we will ignore, for the moment, whether the features are modality-dependent or modalityindependent. The vectors in secondary memory represent the intact list items, as encoded. The residual vectors in primary memory contain features that have been overwritten by adjacent traces with a probability, $F$, set at 0.50. Trace A has its second and fourth features in common with trace $B$, and its second feature value was overwritten; trace $C$, because it was not followed by another list item, remains intact. In this example, and in the simulations that follow, overwritten features are assigned the value of zero.

$\begin{array}{cc}\text { Secondary Memory } & \text { Primary Memory } \\ \text { A: }\left[\begin{array}{cccc}1 & 1 & 1 & 1\end{array}\right] & \text { A: }\left[\begin{array}{cccc}1 & 0 & 1 & 1\end{array}\right] \\ B:\left[\begin{array}{cccc}-1 & 1 & -1 & 1\end{array}\right] & B:\left[\begin{array}{cccc}-1 & 1 & 0 & 1\end{array}\right] \\ C:\left[\begin{array}{cccc}1 & -1 & -1 & 1\end{array}\right] & C:\left[\begin{array}{cccc}1 & -1 & -1 & 1\end{array}\right]\end{array}$

Figure 1. Examples of secondary memory traces and primary memory traces after overwriting.
Grouping. Although it will be mentioned only briefly here, the second variable to influence overwriting, besides similarity, is event grouping: An encoded primary memory trace, $B$, will overwrite the features of trace A if and only if trace $B$ is perceived as belonging to the same list segment as trace $\mathrm{A}$. This means that how a subject chooses to group items, presumably on the basis of global list structure, importantly determines if overwriting occurs, even when two events are highly similar. Similarity is thus viewed as a necessary condition for overwriting to occur, but not a sufficient one (see Frankish, 1985, 1989; Frankish \& Turner, 1984; Kahneman, 1973; Kahneman \& Henik, 1981; Lee \& Estes, 1981; Nairne, 1988). The details of the segmentation process are not known and will not be a general explanatory feature of this model. It is assumed, however, that modality-dependent features play an important role. To represent grouped information the subject needs to be able to discriminate externally based list boundaries, represented as modality-dependent features, from the constant stream of internally generated activity that occurs between the grouped segments.

\section{The Utilization of Trace Information}

At the completion of list presentation, a memory trace for each of the list items is represented in primary memory, but in a degraded form. The subject's first task in recall is to discriminate list traces from internally generated traces, which, I assume, is accomplished by noting the presence or absence of modality-dependent features. The subject then attempts to identify each degraded trace, on the basis of comparisons with the intact secondary memory traces, as described below.

Ordered recall is accomplished by accessing a trace in the order in which it was established. List presentation is represented as a vector of degraded primary memory traces (i.e., a vector of vectors) in which trace order is preserved in the same way that feature positions are preserved in any vector-based representation in memory. If desired, one might conceive of this representational framework in terms of a spatial metaphor. Murdock (1974), for example, has described primary memory as if it contained a conveyor belt moving at constant speed. The occurrence of an event, either externally or internally based, occupies a physical position along the moving belt; retrieval involves the systematic analysis of these objects as they recede backward in time.

The processes that are responsible for the identification of the degraded primary memory trace, once selected, are modeled after those operating in a standard identification paradigm. For each trace in primary memory, the subject seeks to select an appropriate recall candidate from the relevant traces in secondary memory. The latter group defines what is called a secondary memory search set (Raaijmakers \& Shiffrin, 1981) and, in this application, is restricted to the group of most recently presented list items. As Raaijmakers and Shiffrin (1981) noted, the size of a search set is probably influenced by task demands; in the case of serial recall, where small sets of the same 
items are typically rearranged on each trial (e.g., the digits 1 through 9), an appropriately restricted search set seems likely.

Sampling. The probability that a particular secondary memory trace, $S M(j)$, will be sampled, that is, selected as the recall response for primary memory trace $P M(i)$, is a function of a similarity-based choice rule (Luce, 1963; Nosofsky, 1986; Shepard, 1957). Formally, the probability of sampling $\left(P_{s}\right)$ is given by:

$$
P_{s}(S M(j) \mid P M(i))=\frac{w_{j} s(i, j)}{\sum_{k} w_{k} s(i, k)}
$$

where $w_{j}$ and $w_{k}$ are response-bias weights and $s(i, j)$ represents the computed similarity between primary memory trace $P M(i)$ and secondary memory trace $S M(j)$. Following Shepard (1987), similarity is viewed as functionally related to the distance $\left(d_{i j}\right)$ between two trace vectors in some psychological space. In this application, distance was calculated by simply adding the number of mismatched features across the primary and secondary memory trace vectors and dividing by the number of compared features. More formally,

$$
d_{i j}=\frac{a \sum b_{k} M_{k}}{N}
$$

where the index of feature-by-feature mismatches, $M_{k}$, is incremented by one if feature position $x_{i k}$ does not equal feature position $x_{j k}$ and by zero if feature position $x_{i k}$ is the same as feature position $x_{j k} \cdot{ }^{3}$ The value of $a$ is a scaling parameter, $b_{k}$ is an attention parameter that could be used to weight particular feature comparisons (e.g., modality-dependent feature comparisons might be given more weight under some task demands), and $N$ is the number of compared features. This distance measure is then related to similarity according to the function described by Shepard (1987):

$$
s(i, j)=e^{-d_{i j}} .
$$

Each trace vector in primary memory is compared with each of the traces in the secondary memory search set. The similarity values are computed between the primary memory vector and each of the relevant secondary memory vectors, with the probability of sampling a particular vector represented as the ratio of these similarities.

This choice rule, in conjunction with the assumptions outlined earlier, is sufficient to account for the majority of modality-based phenomena of interest here. The likelihood of correctly sampling an item will be greater whenever its corresponding primary memory vector retains features that are distinctive relative to other items in the list. However, to explain the shape of the serial position curve, an additional mechanism is required. For ordered recall, there is a marked primacy advantage that is not handled by the overwriting and sampling functions described so far. Because this primacy advantage is reduced for retention measures requiring partial output (e.g., probe recall or pairwise recognition; see Murdock,
1974), I have chosen to characterize it through output interference, or the negative effect that the recall of one item has on the recall of future items.

Recovery. There are a number of ways to handle output interference in a model employing a choice rule (see Nickerson, 1984, for a review). In the present case, the model follows Raaijmakers and Shiffrin (1981) in its assumption that sampled items need to be recovered prior to recall, and it is in this recovery stage that the locus of output interference resides. However, unlike Raaijmakers and Shiffrin (1981), who assume that recovery is directly related to cue-to-trace strength, in the present case, recovery probability is affected by a prior recall of the to-be-recovered item. More specifically:

$$
P_{r}=e^{-c r},
$$

where $P_{r}$ is the probability of recovering a sampled item, $c$ is a scale constant, and $r$ represents the number of times the sampled item has already been recalled on the current trial. The recovery postulate simply reflects the subject's tendency not to produce an item in recall if the item has already been recalled on that trial. A notable empirical example of this tendency is found in the Ranschberg effect, in which repeated items in a short list show performance decrements relative to unrepeated controls. One popular account of this phenomenon places its locus in subjects' tendencies to restrict their guesses only to items that have not yet been given as responses (see Hinrichs, Mewaldt, \& Redding, 1973). Thus, even though a subject may correctly sample $S M(j)$ given $P M(j), S M(j)$ may not be recovered if that response has been incorrectly recalled earlier during that trial.

\section{The Mechanism of Recency}

Although it might seem reasonable to expect that recall would vary directly with the amount of overwriting a primary memory trace has received, the relationship is not always a direct one. Rather, degrading a trace vector through overwriting lowers its sampling probability only when the loss in similarity of the primary memory trace to its corresponding secondary memory trace is greater than its loss in similarity to other members of the secondary memory search set. It is not the loss of trace information per se that lowers recall, rather it is a corresponding loss in distinctiveness (e.g., Gardiner, 1983; Glenberg \& Swanson, 1986; Nairne, 1988).

To illustrate, consider the simple three-item list shown in Figure 1, where we assumed that primary memory trace $B$ would overwrite half of the features that it shared with primary memory trace A. Table 1 shows the computations for the actual sampling probabilities for item A either with or without the overwriting. For simplicity, the response-bias weights, the scaling parameter, $a$, and the attention weight values have all been set at 1.0 . The probability of sampling $S M(A)$, using $P M(A)$ as a cue, is lower after overwriting, because the loss in $s(A, A)$ is not matched by the same amount of loss in $s(A, C)$. The latter did not change, because the overwritten features were 
Table 1

Computations of Sampling Probabilities

\begin{tabular}{cc} 
Without Overwriting & With Overwriting \\
\hline$d(A-A)=0 / 4=0.00$ & $d(A-A)=1 / 4=0.25$ \\
$d(A-B)=2 / 4=0.50$ & $d(A-B)=3 / 4=0.75$ \\
$d(A-C)=2 / 4=0.50$ & $d(A-C)=2 / 4=0.50$ \\
$s(A-A)=e^{-0.00}=1.00$ & $s(A-A)=e^{-0.29}=0.78$ \\
$s(A-B)=e^{-0.50}=0.61$ & $s(A-B)=e^{-0.75}=0.47$ \\
$s(A-C)=e^{-0.50}=0.61$ & $s(A-C)=e^{-0.50}=0.61$ \\
$P_{S}[S M(A) \mid P M(A)]=\frac{1.0}{1.0+0.61+0.61}$ & $P_{S}[S M(A) \mid P M(A)]=\frac{0.78}{0.78+0.47+0.61}$ \\
& $=0.45$
\end{tabular}

already mismatched between trace $A$ and trace $C$ prior to overwriting. If the overwritten features had been shared by traces $B$ and $C$, no change in sampling probability would have occurred, despite the overall loss of information in trace $A$.

An advantage usually accrues for the last item in a list because its features are followed only by internally generated activities. Thus, the modality-dependent features of the trace, provided they have been encoded, will be intact creating a recency advantage. However, those features must be distinctive for the advantage to occur; if the intact modality-dependent features are "overloaded", in the sense that they occur in all or a number of possible secondary memory traces (Watkins \& Watkins, 1975), then number of features, per se, will not map into a performance advantage. For this reason, increasing the physical similarity among list items leads to a reduction in recency performance during immediate recall (Crowder, 1971, 1978b; M. J. Watkins, O. C. Watkins, \& Crowder, 1974). In a case in which items share a number of modality-dependent features, those features will tend to be overloaded and of limited value in aiding identification.

To summarize, performance advantages are found whenever distinctive modality-dependent features are protected from overwriting either through the lack of subsequently presented material (i.e., the end of the list) or through some kind of segmentation or grouping process. The emphasis is placed on modality-dependent features because it is assumed to be difficult, if not impossible, to protect modality-independent features from overwriting by the ongoing activities of consciousness (Nairne, 1988). Thus, both the appearance of recency and the advantages of grouping in immediate memory tasks are restricted to instances in which distinctive modalitydependent features are present.

\section{Visually Based Traces}

To explain modality-based differences in immediate recall performance, the assessment of visually based memory traces is assumed to depend primarily on modality-independent, rather than modality-dependent, features at the point of recall (for a similar idea, see Penney, 1989). This assumption is based on a rather extensive literature indicating that selective visual interference effects are not typically found with sequential, single- mode presentation conditions of the type of interest here (for reviews, see Frick, 1985; Penney, 1989). It seems possible that visual modality-dependent list features are simply unlikely to be encoded during presentation (that is, $L_{\text {auditory }}>L_{\text {visual }}$ ), leaving the resulting traces with few of the critical components that are necessary for recency and grouping effects. Furthermore, the value of the encoding parameter, $L$, might be influenced by task demands, leading to the appearance of visually based recency effects under some circumstances. For example, if the salience of the visual list features is enhancedperhaps through use of abstract visual stimuli (Broadbent \& Broadbent, 1981) or hand signs (Campbell, Dodd, \& Brasher, 1983) - then $L_{\text {visual }}$ might increase accordingly, and visual recency effects emerge. A similar kind of reasoning can be applied to lip-read and silently mouthed input and their demonstrated recency advantages (see Campbell \& Dodd, 1980; Greene \& Crowder, 1984; Nairne \& Walters, 1983).

Alternatively, one might argue that visual features are encoded, but subjects do not weight them accordingly in determining similarity values. This reasoning follows Nosofsky (1986) and Shepard (1961), who, within the context of identification and classification judgments, suggested that subjects differentially allocate their attentional resources across the dimensions (features) of a stimulus on the basis of task demands or contextual variables. In the case of serial recall, subjects may devote little attention to visually based modality-dependent features, because, under the majority of circumstances, primary memory is best conceived as a vehicle for interpreting and producing spoken language. Although inefficient from the standpoint of remembering the physical aspects of presentation, such a strategy might be quite effective for the overall processing of spoken language. The evidence for speech-like encodings in primary memory with visual presentation is extensive (see Crowder, 1976) and suggests that, in the absence of auditory cues, we likely tend to rely on modality-independent (inner voice) features to reconstruct what stimulus has been presented.

\section{SIMULATION DATA}

This section demonstrates, through computer simulations, that the major modality-based phenomena of interest 
are robust, given the assumptions of the model. Because the qualitative aspects of the effects under study are reasonably well known, the immediate goal was to describe functional relationships rather than precise quantitative form. Quantitative fits of the model to data are desirable, but have not yet been obtained. Points of discrepancy between the simulated data and the known characteristics of serial position curves are noted and, where appropriate, suggestions for improving the fit are made.

\section{Assumptions}

1. Memory traces were represented as vectors containing 20 modality-independent features and, depending on the condition, a variable number of modality-dependent features. A feature value could be either 1 or -1 prior to overwriting; both the modality-independent and the modality-dependent classes contained equal instances of each feature value ( 1 or -1$)$, randomly placed. Because computations of similarity in the model are based only on the presence of mismatched features between compared primary and secondary memory traces, the particular selection of feature values is arbitrary.

2. A vector could be overwritten only by an adjacent event, which, except for the last item in a list, was always another list item. The final item was overwritten by an internally generated trace that contained only 20 modality-independent features. As a consequence, all of the modality-dependent features for the last list item (except when a suffix occurred) remained intact at the point of recall. Furthermore, because it seems likely that $r e$ hearsal of a preterminal item occurs immediately after list presentation, the end-of-the-list internal trace was always composed of the modality-independent features of one of the preterminal items. Each of the preterminal items was assumed to be rehearsed; the actual event varied randomly from trial to trial. Except where noted, the overwriting probability for these simulations was set at 1.0.

3. To determine the similarity values, an overwritten primary memory vector was compared to each of the intact secondary memory vectors (from the immediately preceding list) and the number of mismatching feature values was computed for each comparison. The number of mismatches was divided by the number of compared features; this value was multiplied by the scale parameter, $a$, which was set at 7.0 for the majority of the simulations. The resulting distance values were then adjusted for similarity, according to Equation 3. The sampling probabilities were calculated by dividing the similarity value between the assessed primary memory trace and a given secondary memory vector by the sum of that trace's similarity values to all items on the list. The responsebias weights $\left(w_{j}\right.$ and $\left.w_{k}\right)$ and the attention weighting parameters $\left(b_{k}\right)$ were set at 1.0. For a given trace in primary memory, then, there was a finite probability that any of the secondary memory vectors could be sampled for recall.
4. At this point, the model actually sampled an item for recall, on the basis of the respective sampling probabilities, by randomly selecting a number between 0 and 100 , and by fitting the number into a cumulative probability distribution. The sampled vector was then recovered, or not, according to Equation 4. On the basis of pilot simulations, the decision was made to allow the model two recovery attempts; if the sampled item was not recovered after two consecutive samples, it was classified as an omission error and the simulation proceeded to analyze the next primary memory trace. Any recovered item was assumed to be output successfully in recall and the recovery constant, $c$, was set at 2.00 .

5. The reported data are based on 1,000 simulation trials. Each trial involved the presentation of an eight-item list. The same vectors were repeated as list items from one trial to the next, except that presentation order was determined randomly on each trial.

\section{The Modality Effect}

Figure 2 shows the mean sampling probabilities for the correct item-the item vector that was actually presentedas a function of serial position and number of modalitydependent features. As noted earlier, auditory and visual traces can be assumed to differ in the number of modalitydependent features that play a role in performance. Auditory traces may have a richer collection of physically

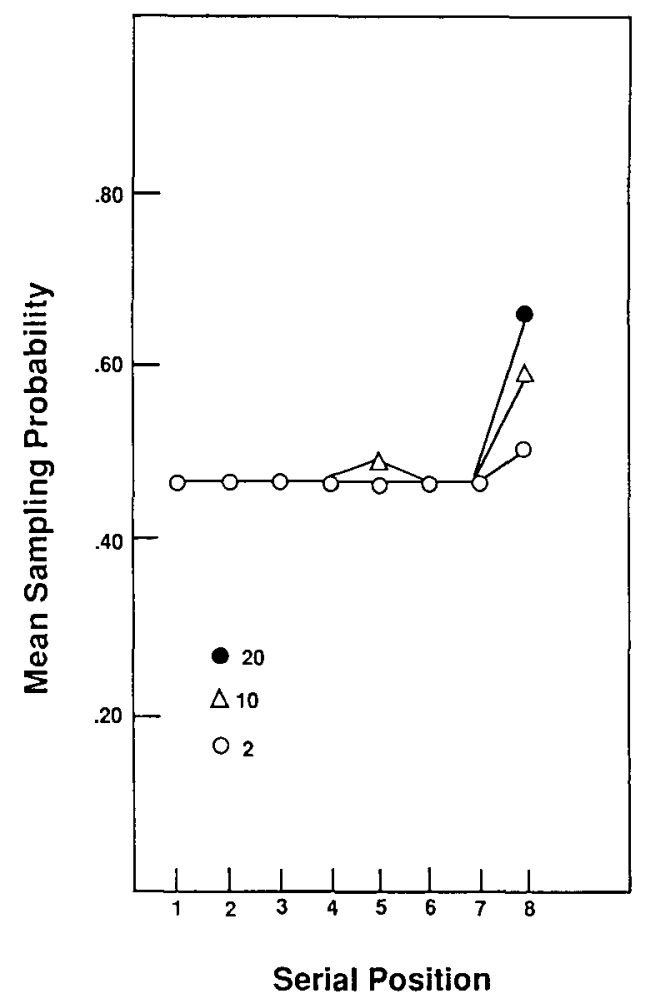

Figure 2. The mean sampling probabilities for the correct item as a function of whether the traces contained 2,10 , or 20 modalitydependent features. 
based features, perhaps because of the inherent coding properties of primary memory. Figure 2 shows how the sampling probabilities are affected when either 2,10 , or 20 modality-dependent features enter into the similarity computations. Very similar values are found for positions 1 through 7 , indicating that number of features has little overall effect on sampling probability. For the last list item, however, there is a sharp recency advantage favoring the vectors containing 20 modality-dependent features. When modality-dependent features are present, sampling probability is higher for the last item in the list, because this item is followed only by internally generated activity that cannot overwrite the modality-dependent features. Visual items presumably do not produce much recency, because visual traces are dominated by modality-independent features, and these features can be overwritten by the internal activity occurring at the end of the list.

Figure 3 shows percent correct recall, representing the effect on performance when the recovery stage (Equation 4) is included in the simulation. Recalled items were scored as correct only if they occurred in their correct serial position. Performance goes down over serial position because the model is less likely to recover a correctlysampled item at the later serial positions, not because there is a greater likelihood of sampling something incorrectly. Performance on the last serial position is the result of a tradeoff between two opposing forces: (1) the greater likelihood of sampling the correct last list item because of the residual modality-dependent features, and (2) the

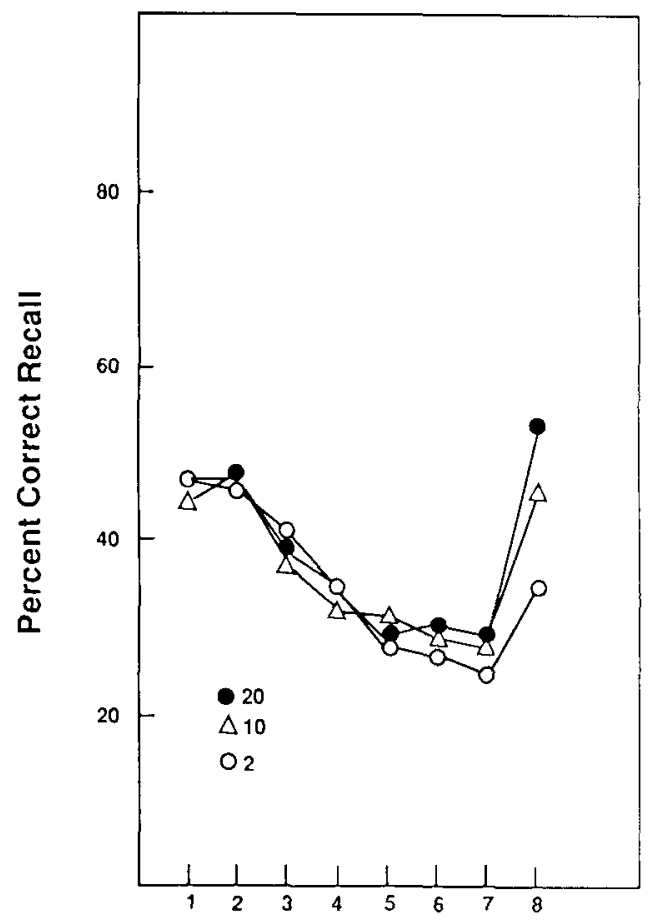

Serial Position

Figure 3. Percent correct recall as a function of whether traces contained 2, 10, or 20 modality-dependent features. reduced likelihood of recovery because that item may well have been recovered previously. The end result is a bowshaped serial position curve with recency varying as a function of presentation modality.

To show that this basic data pattern is not unique to the selection of parameter values, Figures 4 and 5 display the serial position curves for vectors containing 2 or 20 modality-dependent features as a function of changes in the scaling parameter, $a$, found in Equation 2 (see Figure 4 ) and the overall overwriting probability, $F$ (see Figure 5). The general modality effect pattern remains intact across the different simulations, although performance clearly depends on the selection of parameter values. Both the scaling parameter and the overwriting probability affect performance overall, and there is a tendency for recency to decrease as less overwriting is allowed. This last result is understandable because, as the number of remaining features increases, the intact modality-dependent features for the last list item become relatively less predictive. In the limiting case, where the overwriting probability is set at 0.00 , items should have an equal likelihood of being sampled correctly across serial position, because each item vector remains completely intact.

Discrepancies. Although these curves are descriptive of the modality-effect pattern, there are two discrepancies of note. First, there is evidence suggesting that the modality effect may extend across several, rather than just the last, serial positions. The size of this "preterminal" modality effect varies from study to study, and its conditions of occurrence are poorly understood. The feature model might be able to handle such an effect if the range of overwriting was extended beyond adjacent traces; in such a case, externally or internally based activity could overwrite the features of several items in the list vector, rather than just the immediately preceding item. The details of this simulation are complex, however, and have not been explored. The second point of discrepancy is perhaps more interesting because it is diagnostic of the way the model operates. For the serial position curves reported in Figures 3, 4, and 5, there is a tendency for the first and second list items to be recalled at the same level; in most serial position curves, recall of the second item is reliably lower. Equivalent levels of performance are produced by the model because the overwriting of the first item by the second makes the traces maximally dissimilar. Thus, when the overwriting probability is set at 1.0 , there is very little chance of the model incorrectly recalling the second list item when using the degraded vector of the first list item as a cue. This is clearly an unattractive feature of the simulation model because it predicts fewer transposition errors for adjacent items than for remote items in the list; this prediction is counter to the data (see Lee \& Estes, 1977).

\section{The Stimulus Suffix Effect}

The mechanism responsible for the damaging effect of a stimulus suffix is, of course, trace overwriting. The ap- 


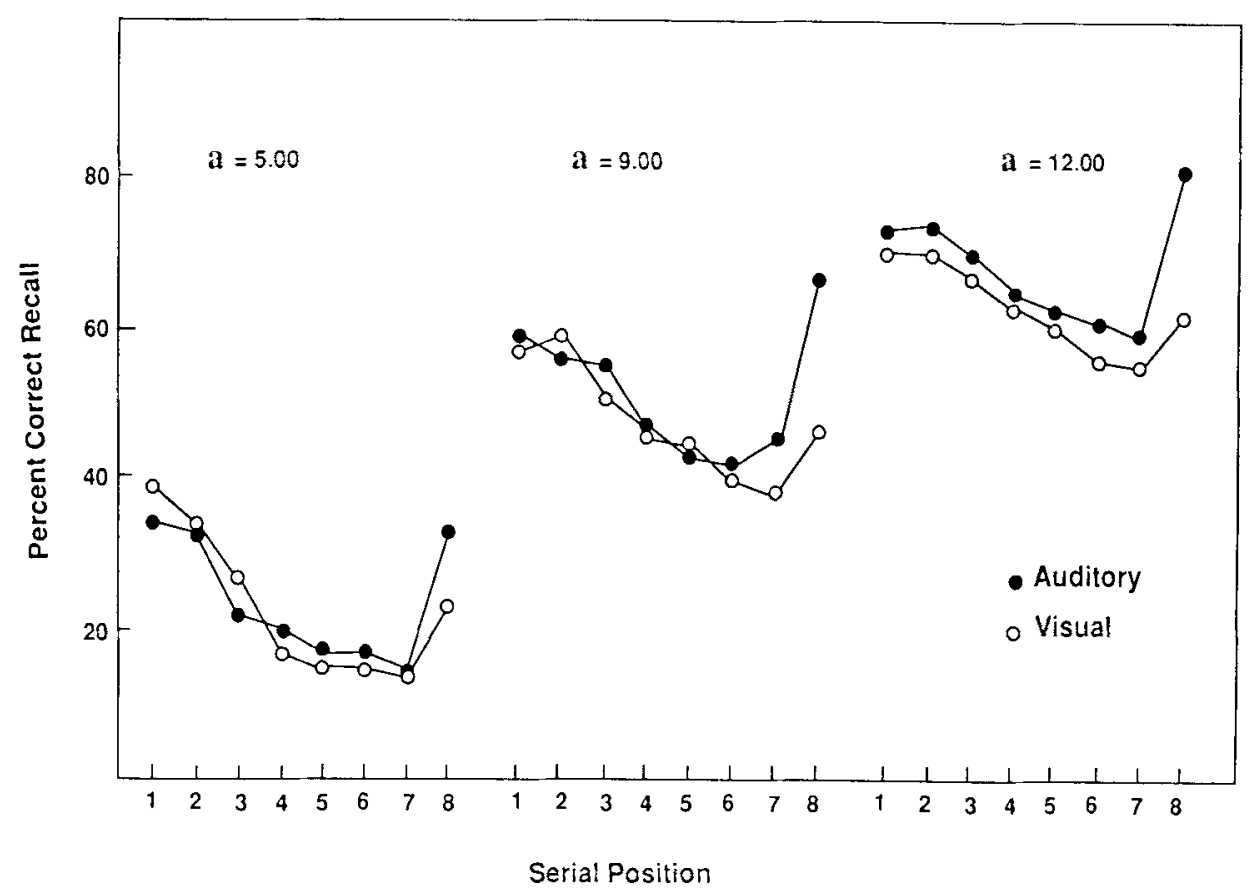

Figure 4. The serial position curves for traces containing 2 or 20 modality-dependent features as a function of changes in the scaling parameter, $a$.

pearance of a stimulus suffix, provided its modalitydependent features are similar to those contained in the list items, will overwrite the corresponding features of the last list item, eliminating any recency advantage. Although the modality-independent features of the last list item are regularly overwritten, at least in part, by subsequent internal activities, it is only through the adminis- tration of a suffix, or some other salient postlist event, that the modality-dependent features of an item can be lost. Furthermore, because the locus of recency lies in these features, a stimulus suffix will be effective in producing interference only to the extent that it is physically, rather than semantically, similar to the last list item (see, e.g., Morton, Marcus, \& Ottley, 1981).

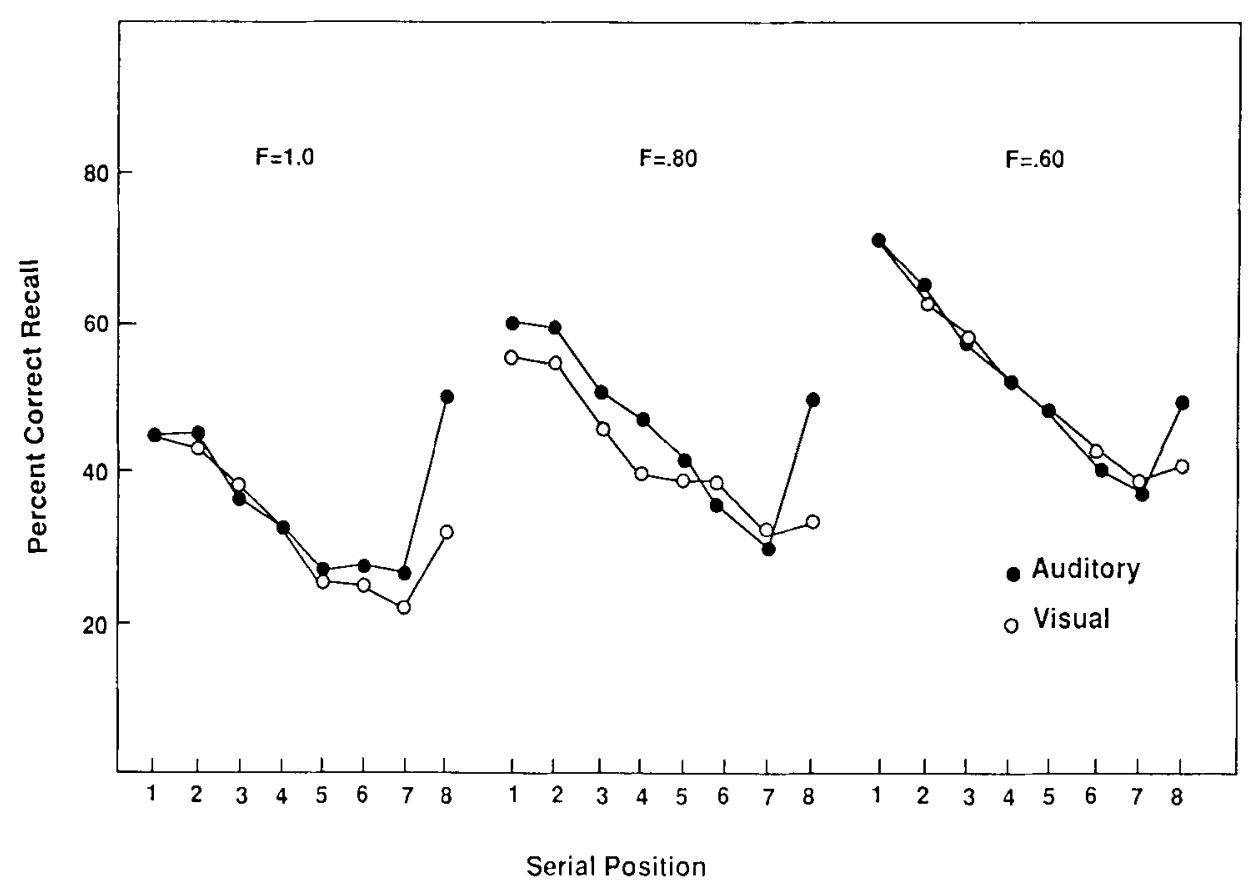

Figure 5. The serial position curves for traces containing 2 or 20 modality-dependent features as a function of changes in the overwriting probability, $F$. 
Figure 6 shows the results of a simulation of the stimulus suffix effect. Instead of following the last list item with an internally generated trace, in the suffix condition a new trace vector was added as if it was the ninth item on the list. The result was twofold: First, the recency effect was eliminated because the eighth item's modality-dependent features were overwritten by the modality-dependent features of the suffix. Second, there was an overall impairment in recall, extending across all serial positions. This kind of "across-the-board" effect is common in the empirical literature, although there is usually somewhat less of an effect for the primacy portions of the list. Balota and Engle (1981) have labeled it the preterminal suffix effect, which they contrasted with the terminal suffix effect in terms of susceptibility to subject-based recall strategies. Penney (1985) has shown, for example, that the predictability of list length can affect whether the suffix impairs performance on preterminal, but not terminal, list items (see also Baddeley \& Hull, 1979).

In the present case, the preterminal suffix effect can be attributed to an increase in the size of the secondary memory search set in the suffix condition. It was assumed that the suffix gained obligatory entry into the set, by virtue of its presentation, and thus sampling probabilities overall were lowered. The net result is something akin to an increase in list length, although it was assumed that the suffix itself could never be recovered for recall. The important thing to note about this interpretation of the preterminal suffix effect is that its locus is different from

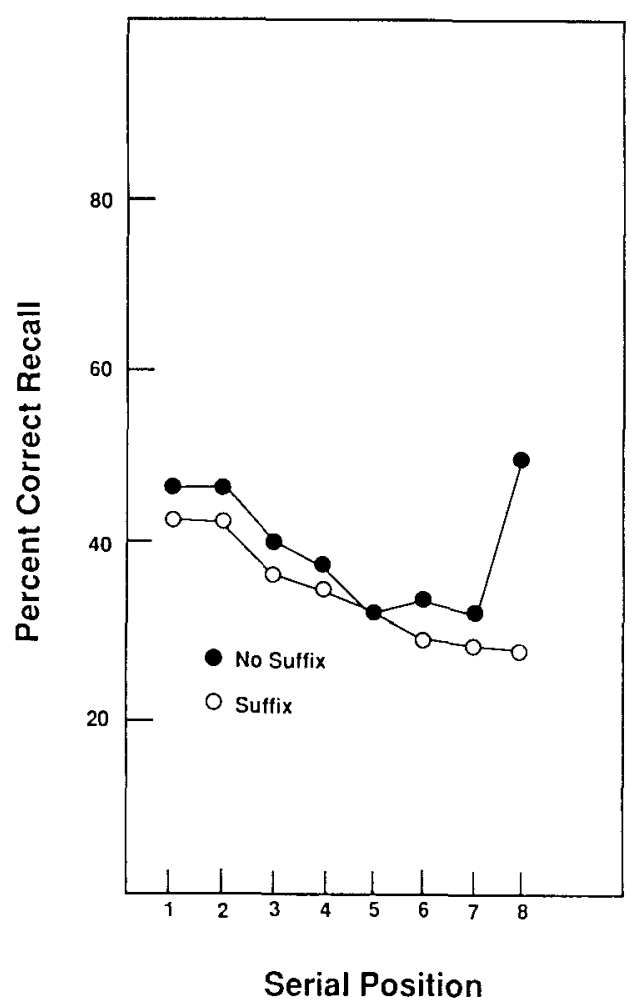

Figure 6. The simulation curves for eight-item lists presented with or without a stimulus suffix. the one proposed for the terminal suffix effect. The latter is caused by automatic overwriting of modality-dependent features (which should not be under strategic control), whereas the former is the result of a functional increase in the size of the search set. A similar analysis might be applied to the response prefix effect, which is produced when the subject is required to emit a redundant verbal item prior to recalling the list (Baddeley \& Hull, 1979); again, there is a general impairment in recall that could be accounted for if one assumed that the emitted response becomes an obligatory member of the secondary memory search set.

\section{Similarity Effects}

Because sampling probability in the feature model is conceived as the ratio of similarities, performance depends importantly on the similarity among items in a list. As similarity increases, either among the modalityindependent or the modality-dependent classes of features, performance in serial recall is impaired (i.e., the denominator of Equation 1 increases relative to the numerator). Thus, the model naturally accounts for the finding that increasing the phonological similarity among items leads to progressive decrements in immediate memory performance (e.g., Conrad \& Hull, 1964). Of more interest in the present application, however, is the role that presentation modality plays in influencing such similarity-based effects.

Auditory recency. One of the critical tests of any theory dealing with modality-based recency effects is to explain why auditory recency is affected by acoustic similarity, but not by semantic similarity (e.g., Crowder, 1976). With respect to semantic factors, it is clear that increasing the semantic similarity among list items (assuming that semantic information is encoded in an immediate memory environment) will not affect relative recency performance, because the last list item does not contain a greater proportion of modality-independent features. Any encoded semantic information about an item is, by necessity, internally generated, and thus is represented as modalityindependent information. Because the constant stream of internally generated activities normally overwrites at least some proportion of the modality-independent features of the last list item, semantic information can play no role in recency performance in serial recall. Rather, the modality-dependent features of a trace dictate whether recency will occur.

Figure 7 shows the results of four groups of simulation trials in which the similarity among the modalitydependent features of list traces was manipulated. Similarity was defined in terms of the number of overlapping features across respective trace vectors. In Condition 10, the 20 modality-dependent features of each trace vector contained 10 features of value 1 and 10 features of value -1 , randomly placed. Similarity was increased among the traces in Condition 15 by assigning the first 10 features the value of 1 and by letting the last 10 features contain 5 features of value 1 and 5 features of value -1 , randomly 


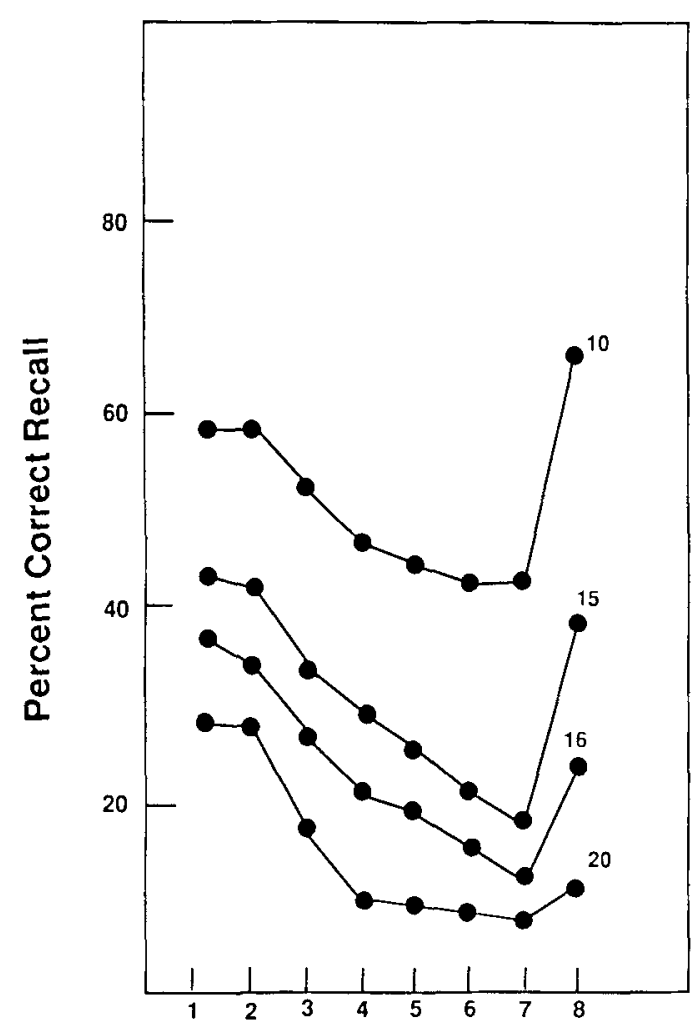

Serial Position

Figure 7. Percent correct recall as a function of similarity and serial position. The numbers defining each condition refer to the number of modality-dependent features that were given the value of 1 .

placed. In Condition 16, the first 12 modality-dependent features were given the value of 1 . In the final instance, Condition 20, all of the modality-dependent features of the trace vectors were the same (each had a value of 1 ). For these simulations, the scaling constant, $a$, was set at 9.00 , in order to avoid flirting with floor effects.

As expected, performance was hurt overall by increasing the similarity among trace vectors. Examination of Figure 8, which shows the mean sampling probabilities, indicates that the impairment can be attributed to the increased likelihood of incorrectly sampling highly similar members of the secondary memory search set, rather than to some special property of the recovery process. Moreover, the data show the expected effect that similarity has on recency performance: As similarity among the encoded trace features increased, the auditory recency advantage was reduced. This trend is particularly evident in Condition 20 , where virtually no recency was obtained. This last condition can be viewed as roughly analogous to presenting homophones visually, but with simultaneous auditory input (e.g., pair, pare, pear). As Crowder (1978b) suggested, when residual auditory information is present, but not informative with respect to determining relative item information, that information cannot be used effectively to determine the identity of the last presented item. In the case of Condition 20, all of the modality-dependent features of the last list vector re- mained intact at the point of recall, yet little or no advantage was found relative to prerecency items. The important predictor of recency is not the number of residual modality-dependent features, but the number of distinctive modality-dependent features.

Articulatory suppression. In addition to explaining recency effects, the feature model is also capable of explaining the finding that phonologically based similarity effects can be eliminated if the subject is required to engage in articulatory suppression (repeating a constant word, such as the) during the visual presentation of the stimulus items (Estes, 1973; Levy, 1971; Peterson \& Johnson, 1971). Theoretical interpretations of this result have usually centered on some kind of recoding argument; that is, articulatory suppression is thought to interfere with our normal ability to recode visual input into a preferred phonological code, which, in turn, affects the functional amount of similarity obtained. If phonological recoding is prevented through suppression and the subject is forced to rely on some other code (possibly visual), then the encoded trace vectors may no longer vary along a similarity dimension-experimenter-defined similarity typically occurs along a phonological dimension, not a visual one (see Baddeley, 1986).

Figure 9 shows a simulation of this pattern of results. Visual traces were used, so the traces were assumed to contain primarily modality-independent features (only two

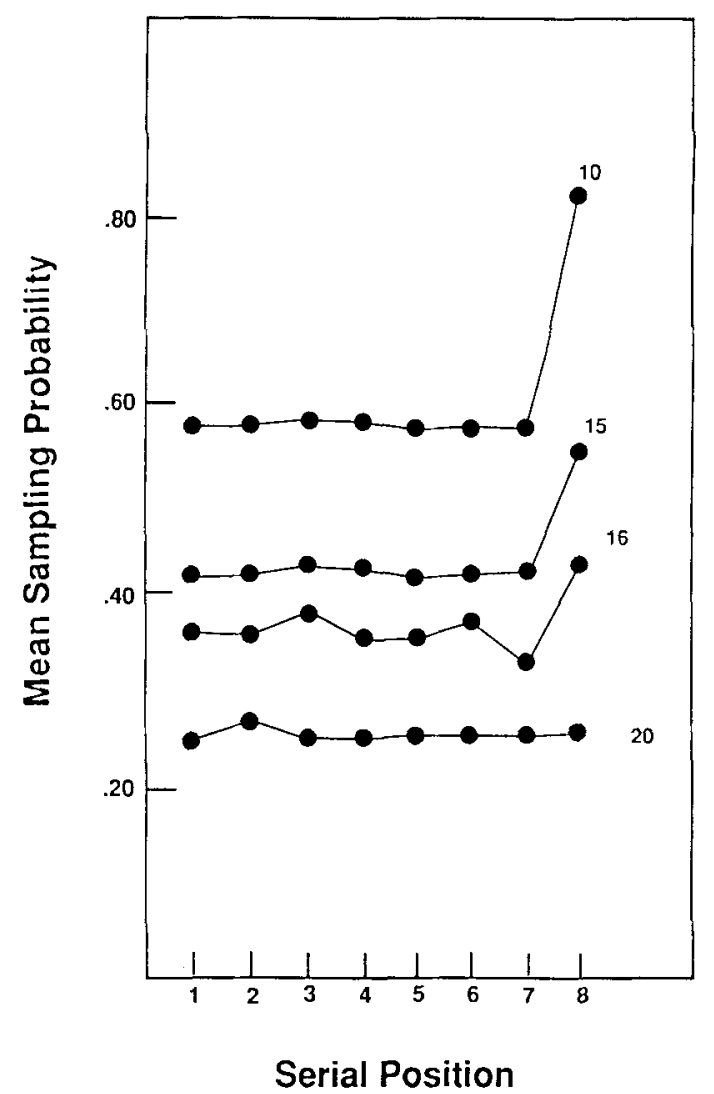

Figure 8. Mean sampling probabilities for the various similarity conditions as a function of serial position. 


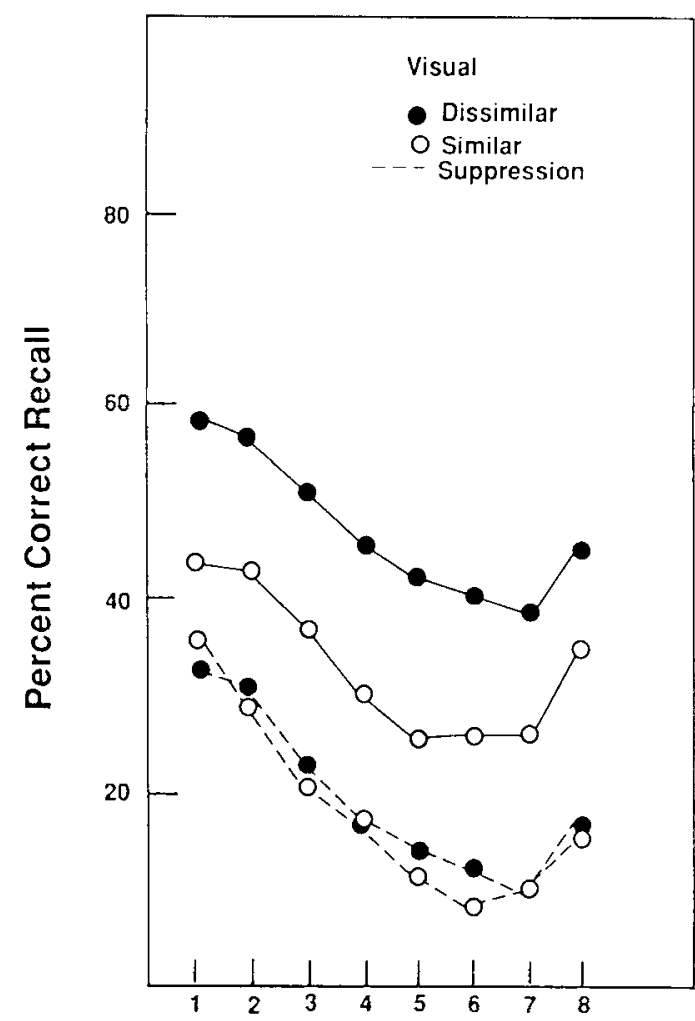

Serial Position

Figure 9. Percent correct recall for simulations using visual traces as a function of similarity (open and closed circles) and articulatory suppression (dashed lines).

modality-dependent features were used). Traces in the dissimilar condition employed an equal number of $1 \mathrm{~s}$ and $-1 \mathrm{~s}$, randomly placed; traces in the similar condition had 15 modality-independent features with the value of 1 and 5 features of value -1 , randomly placed. Once again, increasing the number of overlapping features produced a significant decrement in recall performance.

Of more concern are the data from the articulatory suppression conditions, which are represented in Figure 9 by the dashed lines. The act of repeating a constant throughout presentation was simulated by adding a constant to each of the trace vectors. Specifically, the first 10 modality-independent feature positions for both the similar and the dissimilar traces were filled with the same feature value (zero). The net result was that the total number of common features among the vectors, and hence similarity, was increased. Consistent with the pattern reported by others (e.g., Peterson \& Johnson, 1971), performance was hurt overall by articulatory suppression, and the main effect of similarity disappeared. Collapsing across serial position, the model produced a mean recall level of 0.20 for both the similar and the dissimilar conditions. The decision to simulate suppression in this fashion was based on the idea that internally generated articulation of a redundant unchanging item may become incorporated into the memory record for the to-be-remembered list items. The phonological similarity effect disappeared under articulatory suppression, according to the feature model, because the similar traces already possessed a number of overlapping features; consequently, adding a constant to the vectors produced less of a net increase in similarity than for the dissimilar items. Essentially, articulatory suppression brings the dissimilar and similar items up to a comparable level of similarity. This kind of reasoning not only explains why the phonological similarity effect may disappear under suppression, it also explains why performance is hurt overall.

Figure 10 shows the results of an identical simulation, except that auditory, rather than visual, trace vectors were employed. Exactly the same traces were used, except that each vector contained 20 modality-dependent features in addition to 20 modality-independent features. In the dissimilar condition, both the modality-independent and the modality-dependent classes of features contained 10 features of value 1 and 10 features of value -1 , randomly placed; in the similar condition, there were 15 randomly placed features of value 1 and 5 features of value -1 for each class of features. As before, articulatory suppression was assumed to add a constant value to the first 10 modality-independent features of all traces. Under these conditions, performance was impaired under suppression, but evidence for the phonological similarity effect re-

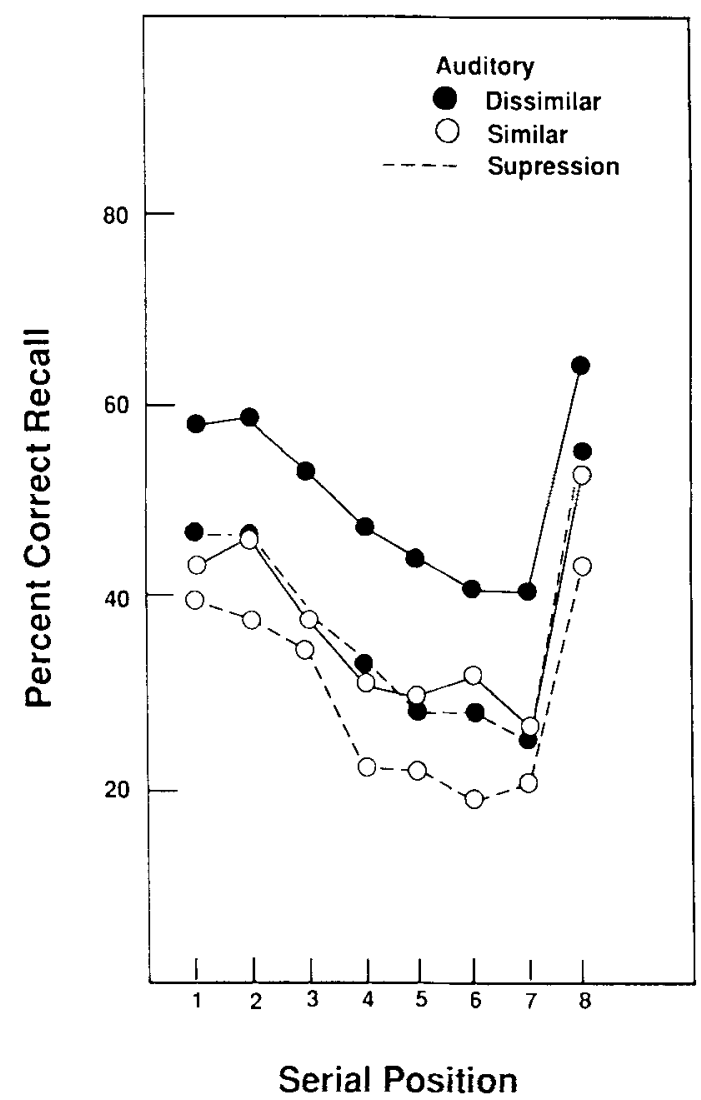

Figure 10. Percent correct recall for simulations using auditory traces as a function of similarity (open and closed circles) and suppression (dashed lines). 
mained: Collapsing across serial position, the dissimilar condition produced a mean recall level of 0.38 , and the similar condition produced a mean recall level of 0.31 . Thus, when modality-dependent features are included, adding a constant amount of similarity fails to make up the intrinsic differences that exist between the similar and dissimilar conditions. The finding that phonological similarity effects remain under articulatory suppression for auditory, but not visual, presentation has been verified empirically in a number of studies (Baddeley, Lewis, \& Vallar, 1984; Peterson \& Johnson, 1971). The fact that this interaction is easily produced with the same set of assumptions about auditory and visual traces that was used to explain other modality-based effects offers strong support for the generality of the feature model.

\section{Modality-Based Grouping Effects}

Although the demonstration of temporal grouping effects has been around for some time (e.g., Ryan, 1969), only recently has it become clear that the modality of presentation plays an important role. Frankish (1985) presented aloud nine-item lists, which were separated into groups of three by the insertion of pauses, and found substantial advantages over ungrouped controls. However, and importantly, the grouping manipulation failed to produce a comparable advantage with silent, visually presented items. Moreover, the beneficial effect of grouping under auditory presentation was present across all serial positions, rather than only at the end of the list, and within each group there were distinct primacy and recency effects (see Ryan, 1969, for a very similar pattern of results). As Frankish (1985) noted, such a pattern of results is inconsistent with rehearsal-based interpretations of grouping: If the presence of extended pauses merely allows for additional rehearsal opportunities, then the advantages of grouping should not depend so critically on presentation modality. Consequently, there are three main findings that need to be addressed by the model: (1) the failure to find grouping advantages for visual presentation, (2) the presence of distinct primacy and recency effects within each aurally presented group, and (3) the presence of a grouping advantage across all serial positions, rather than exclusively at the end.

First, to understand why visual presentation leads to little, if any, grouping effect, it is necessary to consider the nature of the activity that occurs during the temporal interval separating the groups. Any activity that follows a border is part of the internally generated stream of events (probably rehearsal of prior items; see Kahneman, Onuska, \& Wolman, 1968) and, therefore, should be composed of traces containing only modality-independent features. This means that the last item in a temporally separated group should show a performance advantage, because its modality-dependent features will not be overwritten by these internal activities. Because visual traces are proposed to contain very few modality-dependent features (at least in the majority of instances), little advantage should accrue for the last item presented visually in a group. Essentially, the same processes that were used to predict the basic modality effect are therefore employed to explain the differences in recency performance that occur at the end of each temporally separated group.

Although the model predicts a larger grouping advantage for auditory presentation than for visual presentation, some additional mechanisms are necessary to account for primacy effects within groups and for the distribution of grouping advantages across serial position. Because transposition errors (the switching of serial positions) rarely cross the boundaries of a group (see Frick, 1988), one might assume that the secondary memory search set for an assessed primary memory trace is composed only of items that have occurred together in a temporal group. Thus, for a list grouped in threes, the primary memory trace for the first item in the list might be compared with a search set containing traces for just the first three list items. Such a restriction in search-set size should produce a dramatic improvement in recall, depending on the scale parameters chosen, across all serial positions. Furthermore, if the recovery function is assumed to operate only within the confines of a search set (in effect, it is reset for each search set employed), then little, if any, output interference would be expected for the first item in a group.

Figures 11 and 12 show the results of simulation studies based on these ideas. Figure 11 shows the results of a simulation using visual traces, as earlier defined. On half of the trials, a temporal gap was modeled by inserting an internally generated trace, one containing only 20 modalityindependent features, after the fourth item on the list. Because rehearsal of a prior item is likely during the interval, this trace was assumed to contain the modalityindependent features of one of the first three list items. With respect to output interference, the size of the search set was assumed to be the entire list for visual items, because these traces contain few modality-dependent features. As argued previously, it is probably the presence of modality-dependent features that allows one to discriminate externally presented information from the ongoing activities of the inner voice (see Nairne, 1988, pp. 349-350). Consequently, it might prove difficult for the system to restrict search sets based on traces composed primarily of modality-independent features. As expected, the data produced no evidence of a grouping effect for the visual items.

Figure 12 shows the results for simulation trials containing auditory traces. In this case, the vectors contained 40 features and the search sets were restricted to members of a temporally separated group; for the ungrouped control, the search set remained at the size of the list. There are several things to note about the data: First, restricting the size of the set produced a substantial increase in recall that was persistent across all of the serial positions. Second, within each group there were distinct primacy and recency effects, although the mechanisms responsible for each are different. The former is caused by resetting the value of $r$ in the recovery equation to zero 


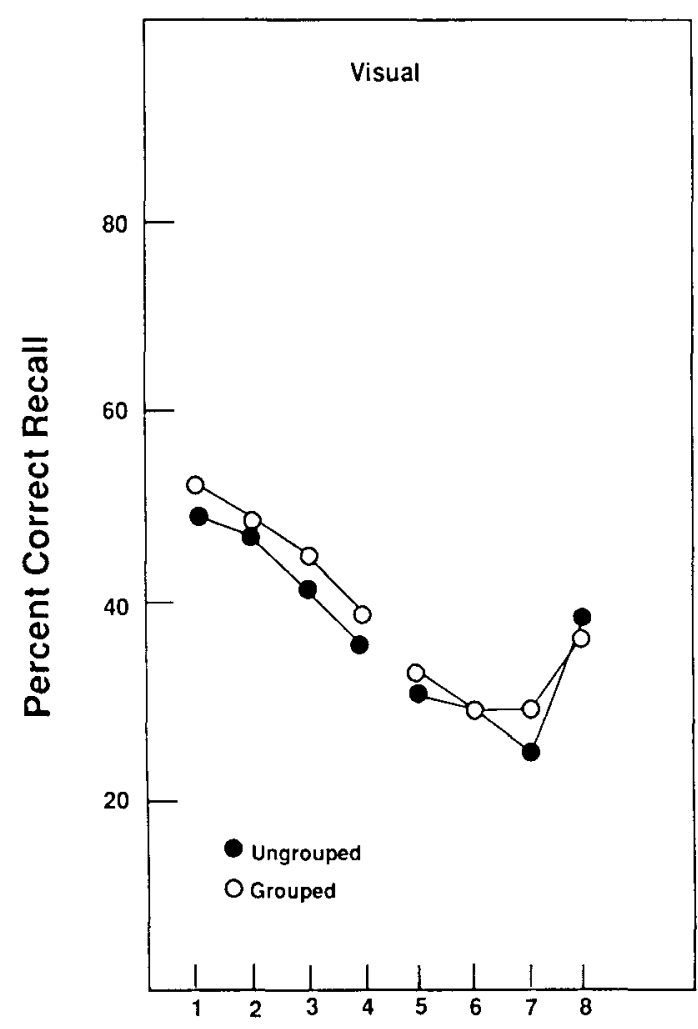

\section{Serial Position}

Figure 11. Percent correct recall of visual traces as a function of whether or not a temporal gap separated the fourth and fifth items on the list.

for each search set employed; the latter is produced by residual modality-dependent features. These data therefore capture, at least qualitatively, the major findings reported by Frankish (1985).

\section{OTHER APPLICATIONS}

To this point, the focus of the simulation studies has been on modality-based effects in immediate memory performance. These particular data domains have been emphasized because they exploit the feature-based properties of the model, and because there exists, at present, no single model that has addressed the range of phenomena of interest here (see Crowder, 1986). Yet, it is important to consider how the model might be extended to handle other problem areas in immediate memory.

\section{Memory Span}

The model has two intrinsic mechanisms that naturally explain why memory performance declines with increasing span (e.g., Crannel \& Parrish, 1957). First, because the size of the secondary memory search set grows directly with list length, primary memory traces will need to be discriminated from increasingly larger pools of candidates; as a result, the sampling probabilities will decrease as the denominators of Equation 1 increase. Second, as more items need to be recalled, there will be greater opportunities for output interference to be engaged. The probability of recovering a sampled item decreases as the number of prior recoveries goes up. These two mechanisms, set-size changes and output interference, can be used to explain the decline in recall with increasing list length. Moreover, because the sampling function is similaritybased, memory span ought to be susceptible to variations in the type of material comprising the to-be-remembered set (see Dempster, 1981, for a review).

More problematic for the feature model are data providing a link between real time and memory span. For example, studies of the word length effect suggest that the probability of correctly recalling a list depends on the amount of time that it takes a subject to recite it (Baddeley, Thomson, \& Buchanan, 1975; Schweickert \& Boruff, 1986). These data have been used to support the role of decay in immediate memory, which presumably is counteracted through the use of subject-based rehearsal strategies. Although it would be possible to simulate the word length effect in the feature model by manipulating interitem similarities, such an approach lacks intuitive appeal. Instead, the model needs to be expanded in some way to pinpoint how trace accessibility might vary with

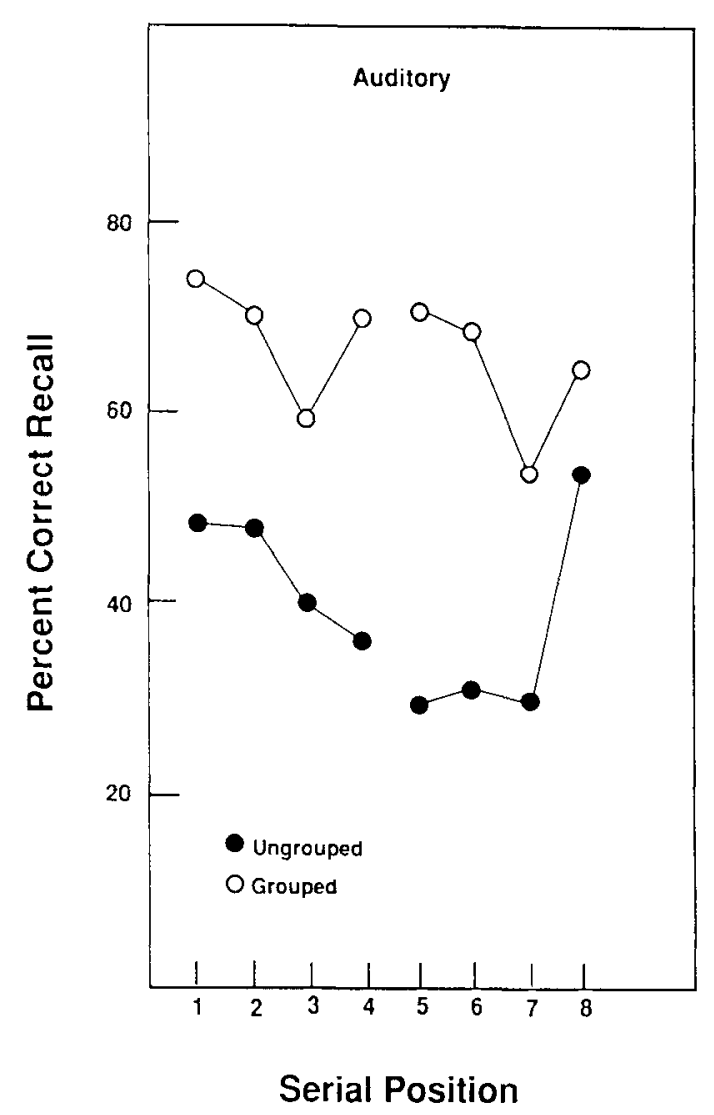

Figure 12. Percent correct recall of auditory traces as a function of whether or not a temporal gap separated the fourth and fifth items on the list. 
the passage of time. One possible extension is considered in the next section.

\section{Item and Order Data}

Order errors in the feature model are derivative of the identification process and occur whenever subjects incorrectly identify degraded primary memory traces as alternative members of the secondary memory search set. Order errors are dependent on similarity, as in the earlier serial recall models of Conrad (1965) and Murdock (1983; see also Lewandowsky \& Murdock, 1989), so transposition errors are likely outcomes of the identification and recall processes. If a sampled item fails to be recovered successfully, then an omission error occurs; omission errors can result even if the correct member of the search set has been sampled.

At present, no attempt has been made to fit the feature model to the actual item and order error distributions that have been obtained (e.g., Bjork \& Healy, 1974), but a straightforward application seems unlikely to be successful. However, for the modality-based phenomena of interest, it was necessary to assume only a very simpleminded mechanism for the preservation of ordered input; namely, degraded primary memory traces were assumed to be ordered in a vector representation and each was accessed in its order of appearance. A natural extension of the model would be to introduce complexity into the representation process, perhaps along the lines suggested by Estes (1972) in his perturbation model (see also, Lee \& Estes, 1981). In such a model, trace order is controlled by a hierarchical coding scheme, and subordinate traces or features are subject to random perturbations as a function of time. With each tick of the clock, there is some probability that adjacent traces or features will swap locations in the vectors, producing a steady loss in order information as a function of time. Not only would such a scheme be capable of explaining time-dependent effects, it also produces response-position gradients that are well matched by the data (see Lee \& Estes, 1977).

\section{Repetition Effects}

Item repetition has a powerful influence on retention, regardless of whether the memory task is immediate or occurs after a lengthy delay. In the immediate serial recall literature, however, it is important to differentiate between the effect of item repetition within a list and repetition of the same set of items across different trials. In the former case, repetition of the same item intralist can produce an inhibitory effect (the Ranschberg effect); in the latter case, as first documented by Hebb (1961), there is a gradual improvement in overall recall as the list is repeated from one trial to the next (known as the Hebb repetition effect).

The inhibitory effect of intralist repetition is a straightforward prediction of the recovery postulate of the feature model. The probability of successfully recovering a sampled item decreases if that item has been recovered previously. Thus, repeated items, even if sampled correctly, are unlikely to be produced in recall. Note that the locus of this inhibitory effect is in the second occurrence of the item, which is one of the defining characteristics of the Ranschberg effect (e.g., Jahnke, 1969). Application of the model to the Hebb repetition effect is less clear. The feature model is unequipped to handle this phenomenon, because there is no mechanism to explain long-term "learning" of the type that may occur across trials. Cunningham, Healy, and Williams (1984) have shown, for example, that repetition effects in the Hebb paradigm depend on elaborative processing of the list in preparation for recall. Accordingly, the Hebb repetition effect is probably attributable more to secondary memory processes than to primary memory.

There are other trial-by-trial changes, however, that are easily handled by the mechanics of the model. In the case of proactive inhibition, recall performance typically declines across trials, often as a function of the intertrial similarity of the to-be-remembered events (e.g., Wickens, Born, \& Allen, 1963). In such a case, subjects may tend to focus their attention-represented in the model as the attention weight parameter, $b_{k}-$ on the relevant stimulus dimension that is consistent from trial to trial (e.g., semantic class). The net result increases the functional similarity of the encoded traces over trials and, as a result, decreases recall performance. Furthermore, if the relevant stimulus dimension is changed, either before or after event presentation (Gardiner, Craik, \& Birtwistle, 1972), then attention might be directed more uniformly across the stimulus features and the net interitem similarity should be less. The improvement in recall performance that occurs when there is a shift in the relevant stimulus dimension is, of course, referred to as release from proactive inhibition (e.g., Wickens, 1972).

\section{Brown-Peterson Data}

Although the feature model is designed to deal primarily with the effects of immediate serial recall, it can be easily expanded to handle delayed recall effects of the type found in the Brown-Peterson distractor task (Brown, 1958; Peterson \& Peterson, 1959). In this case, to-beremembered information is recalled after varying periods of distraction (e.g., counting backwards by threes) and performance declines as a function of the length of the distraction period. Such a pattern could be modeled with the same two mechanisms that were used for the stimulus suffix effect. First, the distractor task itself should overwrite at least some of the list information, and the interference obtained should depend on similarity (e.g., Elliott \& Strawhorn, 1976). Second, if one assumed that the distractor material gained access to the secondary memory search set (see Murdock, 1966, for the relevant evidence), then performance should decline as length of distraction increases; a similar mechanism was used to explain the across-the-board effects of the stimulus suffix on serial recall.

\section{Isolation Effects}

Another phenomenon that has been of some importance historically is the Von Restorff effect, in which isolated 
items within a list are found to be especially well recalled. The conspicuous nature of the item, of course, is defined by its lack of overlap with other members of the recall set, so its recall advantage is easily explained by the feature model. Items that are distinctive within the recall set should receive less overwriting and should be easily discriminated from competitors during sampling. The occurrence of the Von Restorff effect in immediate memory settings is another example of the powerful influence of similarity on immediate memory retention and provides strong support for similarity-based models of the recall process.

\section{Summary}

This section has described a sampling of other phenomena that might well be handled by the already intact assumptions of the feature model. In most cases, the recall effects are natural derivations of the sampling and recovery processes and require no further ad hoc assumptions. In other cases, however, further theoretical development is necessary, especially with respect to the representation of vector order in primary memory. The representation of order information has been the primary focus of past serial recall models (e.g., Estes, 1972; Murdock, 1983; Shiffrin \& Cook, 1978), but these models have yet to be extended successfully to modality-based effects. A marriage of these ideas with the present notions about sampling and recovery processes was suggested.

\section{COMPARISONS WITH OTHER PERSPECTIVES}

In this section, I consider some other perspectives on modality-related effects and discuss their resemblance to the current approach. My intention is to trace the intellectual lineage of the feature model, thereby highlighting the similarities that exist with past work. In many respects, the feature model can be viewed as an amalgamation of past ideas.

\section{Echoic Persistence}

The dominant interpretation of the modality and suffix effects during the 1970s and early 1980 s was the precategorical acoustic storage (PAS) model of Crowder and Morton (1969). The key assumption of the PAS model was the proposed existence of a precategorical, acoustic sensory memory store. PAS, as the store has come to be called, was capable of prolonging the physical sound produced by external input for a longer duration than its counterpart in the visual system (i.e., iconic memory). Given that the individual could make use of this physical "echo"- -either through a kind of "dress rehearsal" of the last list item (Crowder, 1978a) or through direct utilization at the time of test (Morton, 1970; Watkins \& Watkins, 1980)-improved retention of the last item or two in the list was expected.

One of the frequently cited advantages of the PAS model is its ability to explain both the modality effect and the suffix effect with the same mechanism, namely, persistent echoic information. The presentation of a stimulus suffix acted to reduce the auditory recency advantage because PAS was limited in capacity and, thus, information could be easily disrupted or overwritten by subsequently occurring material. The idea of residual auditory trace information that can be easily overwritten by subsequently occurring material is basic to the notions suggested here. However, rather than placing the locus of echoic persistence in a hypothetical memory structure (i.e., PAS), the feature model more closely resembles the view offered by Watkins and Watkins (1980) that the "echoic and nonechoic representations of an item should not be thought of as separate entities, but rather as different aspects of a common memory 'trace"' (p. 274). Memory traces are thus conceived as containing both precategorical and postcategorical components that, in the present case, are selectively overwritten by subsequently occurring material.

There are other ways in which the feature model makes use of important components of the PAS perspective. For example, Crowder (1978b) stressed how the utilization of persistent echoic information depends on its distinctiveness. The similarity-based choice rule, which governs sampling probability in the model, is one way of formalizing Crowder's (1978b) ideas. In addition, the Watkins and Watkins (1980) proposal that residual echoic information is utilized directly at the time of test is included, although a very specific characterization of how this utilization occurs is provided.

The key difference between the present approach and the PAS perspective lies in the use of modality-dependent features: Rather than tying echoic persistence to the special properties of sound, it is assumed that we represent the general conditions of presentation, regardless of the modality involved. The modality-dependent attributes of a trace will then persist in the absence of interfering material and, depending on the task demands of the experiment, will be more or less likely to be used as discriminative cues in recall. Such an assumption allows the model to incorporate the recent lipreading and silentmouthing studies, as well as the instances in which visual presentation yields significant recency effects (see Nairne, 1988, for a further discussion of this point).

\section{Stimulus-Based Theories}

There are other accounts that appeal to the special properties of a presented stimulus, but the appeal is neither to sound nor to the persistence of a stimulus quality. In Shand and Klima's (1981) primary linguistic code hypothesis, the representational format of information in primary memory dictates whether presentation modes will promote recency. The basic idea is that, whenever information is presented in a manner consistent with the primary linguistic code (acoustic for hearing subjects and sign-based for deaf subjects), little, if any, recoding of the information is required. Like Shand and Klima's (1981) model, the feature model assumes that the primary 
mode of communication, and consequently the dominant coding format of information in primary memory, may affect the likelihood that recency will be obtained. Its locus in the present case, however, is in the likelihood that certain trace attributes will be used in determining the similarity values that influence recall. For example, it has been suggested that visually based modality-dependent features may not receive much attention under the majority of circumstances because primary memory is normally an acoustically based environment (see Nairne, 1988, p. 348). For deaf subjects, of course, visually based features may be weighted more heavily, and visual recency effects may be expected. Thus, some consideration of our normal tendencies to rely on speech-based information is a necessary element of any theory of modality effects.

\section{Temporal Coding}

As an alternative to the notion of echoic persistence, a number of authors have attempted recently to relate the concept of temporal coding to modality-based phenomena in memory. Such theoretical positions have tended to argue either that time-of-occurrence information is better represented in the auditory mode (e.g., Gardiner, 1983; Gardiner \& Gregg, 1979; Glenberg \& Swanson, 1986) or that the auditory mode is somehow better equipped to handle the retention of serial order information, perhaps through some kind of temporal order coding (e.g., Drewnowski \& Murdock, 1980; Metcalfe, Glavanov, \& Murdock, 1981).

The idea that time-of-occurrence information is stored as a fundamental attribute of a primary memory trace has been around for some time (e.g., Yntema \& Trask, 1963), but only recently has it been applied to modality-based effects. Following up on some speculations by Gardiner (1983), Glenberg and Swanson (1986) proposed that timeof-occurrence information is specified more precisely for auditory events. As a result, auditory traces tend to be more temporally distinctive than visual ones, leading to superior retention performance under some circumstances. Of interest to Glenberg and Swanson (1986) was a phenomenon known as the long-term modality effect, in which studied items and the beginning of free recall are separated by distractor-filled intervals (Bjork \& Whitten, 1974). Under such conditions, significant long-term recency is obtained, but more so for auditory than for visual presentation (see Gardiner \& Gregg, 1979; Glenberg, 1984; Glenberg \& Fernandez, 1988; Glenberg \& Swanson, 1986; Greene, 1985).

In a recent article (Nairne, 1988), I outlined how this idea of greater precision in temporal coding might be justified given the present assumptions about the trace representations of auditory and visual events. Briefly, if one assumes that visually based traces are composed of primarily modality-independent features, then time-ofoccurrence information might be associated with a wider temporal region, because there is an abundance of inner voice activity that occurs immediately before and after stimulus presentation. Although the occurrence of audi- tory traces, based on an analysis of modality-dependent features, could be distinguished from these inner voice activities, a similar discrimination should prove difficult for visual traces. Thus, less precision in the representation of occurrence information is expected for visual items (a comparable assumption was adopted earlier in the discussion of grouping). If one further assumed that the "time tag"' is associated with the modality-dependent class of features, then not only would less overwriting be expected for auditory traces (the time tags would be less similar from one trace to the next), but any remaining time tags would be more helpful (distinctive) in the choosing of the appropriate member of the auditory-based search set.

A somewhat different idea, also discussed by Gardiner (1983), is that the auditory modality might be especially equipped to process information about serial order, as defined by the relative positioning of items within a list. In such a case, the locus of modality-based effects in immediate memory is placed in the retention of order, rather than in item information (see Healy, 1982). Among the evidence used to support this position is Metcalfe et al.'s (1981) finding that the auditory mode leads to better temporal order performance, whereas the visual mode is superior in the retention of spatial order. Also, Drewnowski and Murdock (1980) found that auditory presentation yielded better serial positioning performance under conditions in which all of the item information present in the list had been recalled correctly.

One attempt to provide a specific accounting of the temporal order idea can be found in Drewnowski's (1980) attribute model. His model resembles the present one in its assumption that feature-based traces, rather than individual items, form the basic units of analysis. Furthermore, a trace's auditory attributes are influenced by distinctiveness and play a critical role in producing modality differences in immediate memory. Auditory attributes in the Drewnowski (1980) model are unique, however, in that they provide "directional" information that enables subjects to improve their retention of an item's relative position in a list. Auditory attributes therefore provide information about ordered recall that is independent of memory for the individual item per se. Auditory attributes in the feature model, of course, do not supply unique mnemonic information; they are perhaps more salient under most circumstances, or more likely to receive processing attention, but these properties are not absolute. Under the appropriate task demands, one can expect any form of modality-dependent information to improve performance. Such flexibility allows the proposed model to handle a variety of modality-based effects (e.g., visual recency, grouping, articulatory suppression, etc.) that are not clearly addressed by the Drewnowski (1980) model.

\section{SUMMARY AND CONCLUSIONS}

In this article, a feature model has been described and used to interpret a broad range of modality-based effects 
in immediate recall. Basic to the model is the distinction between two qualitatively different classes of trace features: (1) modality-dependent features, which represent the conditions of presentation, and (2) modality-independent features, which accrue from the internally generated processes of identification and categorization. These features were suggested to play a critical role in helping subjects decode residual information in primary memory, which had been previously overwritten by either internally or externally generated events. The recall process was proposed to be based on the sampling and recovery of information from secondary memory search sets; the sampling process was defined in terms of a similaritybased choice rule. It was argued that these assumptions may well provide a realistic depiction of the mechanics of primary memory: Primary memory is represented here as a continuous stream of internally and externally generated activity, rather than as a box containing experimenterdefined items that sit in a kind of mental vacuum. Clearly, any complete account of immediate memory needs to take into account how subjects can tell the difference between these internally and externally generated events, and the ramifications of their interactions on retention.

In support of the model, the reported simulations showed how a variety of previously unrelated phenomena could be accounted for, using a common set of assumptions. The simulation model employed a relatively small number of parameters (many of the general parameters were set at 1.0 ), and the simulations were conducted without major changes in parameter values from one simulation to the next. Perhaps more importantly, the feature model is composed of modeling techniques that are the cornerstones of a number of other highly successful models of long-term retention and categorization (e.g., Hintzman, 1986; Raaijmakers \& Shiffrin, 1981). Approaches such as the present one therefore hold the promise of tying together the immediate memory research with recent advances in these other areas. Finally, as the last section documents, the proposed feature model is a direct intellectual descendant of past theoretical formulations about the mechanisms of immediate memory. As a result, a close correspondence has been maintained between the formal processes of the simulations and the psychological basis of primary memory. The link between the psychology of our models and their formal computational techniques is an important one and is, of course, fundamental to progress in the field of cognitive science.

\section{REFERENCES}

Atkinson, R. C., \& Shiffrin, R. M. (1971). The control of short-term memory. Scientific American, 225, 82-90.

BADDELEY, A. D. (1986). Working memory. Oxford: Oxford University Press.

Baddeley, A. D., Hull, A. (1979). Prefix and suffix effects: Do they have a common basis? Journal of Verbal Leaming \& Verbal Behavior, 18, 129-140.

Baddeley, A. D., LewIs, V. J., \& VAllar, G. (1984). Exploring the articulatory loop. Quarterly Journal of Experimental Psychology, 36, 233-252.

Baddeley, A. D., Thomson, N., \& Buchanan, M. (1975). Wordlength and the structure of short-term memory. Journal of Verbal Learning \& Verbal Behavior, 14, 575-589.

Balota, D. A., \& ENGLE, R. W. (1981). Structural and strategic factors in the stimulus suffix effect. Journal of Verbal Learning \& Verbal Behavior, 20, 346-357

BJoRK, E. L., \& HEALY, A. F. (1974). Short-term order and item retention. Journal of Verbal Learning \& Verbal Behavior, 13, 80-97.

Bjork, R. A., \& Richardon-Klavehn, A. (1989). On the puzzling relationship between environmental context and human memory. In C. Izawa (Ed.), Current issues in cognitive processes: The Tulane Flowerree symposium on cognition (pp. 313-344). Hillsdale, NJ: Erlbaum.

BjoRK, R. A., \& Whitten, W. B. (1974). Recency-sensitive retrieval processes in long-term free recall. Cognitive Psychology, 6, 173-189.

BOWER, G. H. (1967). A multicomponent theory of the memory trace. In K. W. Spence \& J. T. Spence (Eds.), The psychology of learning and motivation (Vol. 1, p. 230-325). New York: Academic Press.

Broadbent, D. E., \& Broadbent, M. H. P. (1981). Recency effects in visual memory. Quarterly Journal of Experimental Psychology, 33A, $1-15$.

Brown, J. (1958). Some tests of the decay theory of immediate memory. Quarterly Joumal of Experimental Psychology, 10, 12-21.

CAMPBell, R., \& DodD, B. (1980). Hearing by eye. Quarterly Journal of Experimental Psychology, 32, 85-99.

CAMPBell, R., Dodd, B., \& Brasher, J. (1983). The sources of visual recency: Movement and language in serial recall. Quarterly Journal of Experimental Psychology, 35A, 571-587.

Conrad, R. (1964). Acoustic confusions in immediate memory. British Journal of Psychology, 55, 75-84.

Conrad, R. (1965). Order error in immediate recall of sequences. Journal of Verbal Learning \& Verbal Behavior, 4, 161-169.

Conrad, R., Hull, A. J. (1964). Information, acoustic confusions and memory span. British Journal of Experimental Psychology, $\mathbf{5 5}$ $429-432$

Conrad, R., \& Hull, A. J. (1968). Input modality and the serial position curve in short-term memory. Psychonomic Science, 10, 135-136.

Corballis, M. C. (1966). Rehearsal and decay in immediate recall of visually and aurally presented items. Canadian Journal of Psychology, 20, 43-51

Craik, F. I. M. (1969). Modality effects in short-term memory. Journal of Verbal Learning \& Verbal Behavior, 8, 658-664.

Crannel, C. W., \& Parrish, J. M. (1957). A comparison of immediate memory span for digits, letters, and words. Journal of Psychology, 44, 319-327.

Crowder, R. G. (1971). The sounds of vowels and consonants in immediate memory. Journal of Verbal Learning \& Verbal Behavior, 10 , 587-596.

Crowder, R. G. (1976). Principles of leaming and memory. Hillsdale, NJ: Erlbaum.

Crowder, R. G. (1978a). Mechanisms of backward masking in the stimulus suffix effect. Psychological Review, 85, 502-524.

Crowder, R. G. (1978b). Memory for phonologically uniform lists. Journal of Verbal Learning \& Verbal Behavior, 17, 73-89.

Crowder, R. G. (1986). Auditory and temporal factors in the modality effect. Journal of Experimental Psychology: Learning. Memory, \& Cognition, 12, 268-278.

Crowder, R. G., \& Morton, J. (1969). Precategorical acoustic storage (PAS). Perception \& Psychophysics, 5, 365-373.

Cunningham, T. F., Healy, A. F., \& Williams, D. M. (1984). Effects of repetition on short-term retention of order information. Joumal of Experimental Psychology: Leaming. Memory, \& Cognition, 10, 575-597.

Dallett, K. M. (1965). "Primary memory": The effects of redundancy upon digit repetition. Psychonomic Science, 3, 237-238,

DemPSTER, F. N. (1981). Memory span: Sources of individual and developmental differences. Psychological Bulletin, 89, 63-100.

DREWNOWSKI, A. (1980). Attributes and priorities in short-term recall: 
A new model of memory span. Journal of Experimental Psychology: General, 109, 208-250.

DrewnowskI, A., \& MURDoCK, B. B., JR. (1980). The role of auditory feature in memory span for words. Journal of Experimental Psychology: Human Learning \& Memory, 6, 319-332.

Erch, J. M. (1982). A composite holographic associative recall model. Psychological Review, 89, 627-661.

Elliott, L. A., \& Strawhorn, R. J. (1976). Interference in shortterm memory from vocalization: Aural versus visual modality differences. Journal of Experimental Psychology: Human Learning \& Memory, 2, 705-711.

EsTES, W. K. (1972). An associative basis for coding and organization in memory. In A. W. Martin \& E. Martin (Eds). Coding processes in human memory (pp. 161-190). Washington, DC: Winston.

Estes, W. K. (1973). Phonemic coding and rehearsal in short-term memory. Journal of Verbal Leaming \& Verbal Behavior, 12, 360-372.

Estes, W. K. (1980). Is human memory obsolete? American Scientist, 68, 62-69.

FranKISH, C. (1985). Modality-specific grouping effects in short-term memory. Journal of Memory \& Language, 24, 200-209.

FrankISH, C. (1989). Perceptual organization and precategorical acoustic storage. Journal of Experimental Psychology: Learning, Memory, \& Cognition, 15, 469-479.

Frankish, C., \& TURNer, J. (1984). Delayed suffix effects at very short delays. Journal of Experimental Psychology: Learning, Memory, \& Cognition, 10, 767-777

Frick, R. W. (1985). Testing visual short-term memory: Simultaneous versus sequential presentations. Memory \& Cognition, 13, 346-356.

FrICK, R. W. (1988). Issues of representation and limited capacity in the auditory short-term store. British Journal of Psychology, 79, 213-240.

Gardiner, J. M. (1983). On recency and echoic memory. Philosophical Transactions of the Royal Society of London, 302, 267-282.

Gardiner, J. M., Craik, F. I. M., \& BirTwistle, J. (1972). Retrieval cues and release from proactive inhibition. Journal of Verbal Learning \& Verbal Behavior, 11, 778-783.

Gardiner, J. M., \& GregG, V. H. (1979). When auditory memory is not overwritten. Journal of Verbal Learning \& Verbal Behavior, 18, 705-719.

Geiselman, R. E., \& Bjork, R. A. (1980). Primary versus secondary rehearsal in imagined voices: Differential effects on recognition. Cognitive Psychology, 12, 188-205.

Gillund, G., \& SHIFFrin, R. M. (1984). A retrieval model for both recognition and recall. Psychological Review, 91, 1-67.

GlenberG, A. M. (1984). A retrieval account of the long-term modality effect. Journal of Experimental Psychology: Learning, Memory, \& Cognition, 9, 231-255.

Glenberg, A. M., \& Fernandez, A. (1989). Evidence for auditory temporal distinctiveness: Modality effects in order and frequency judgments. Journal of Experimental Psychology: Learning, Memory, \& Cognition, 14, 728-737.

GlenberG, A. M., \& Swanson, N. G. (1986). A temporal distinctiveness theory of recency and modality effects. Journal of Experimental Psychology: Learning, Memory, \& Cognition, 12, 3-15.

GreENE, R. L. (1985). Constraints on the long-term modality effect. Journal of Memory \& Language, 24, 526-541.

GreEne, R. L., \& CRowder, R. G. (1984). Modality and suffix effects in the absence of auditory stimulation. Journal of Verbal Learning \& Verbal Behavior, 23, 371-382.

Healy, A. F. (1982). Short-term memory for order information. In G. H. Bower (Ed.), The psychology of learning and motivation (Vol. 16, pp. 191-238). New York: Academic Press.

HEBB, D. O. (1961). Distinctive features of learning in the higher animal. In J. F. Delafresnaye (Ed.), Brain mechanisms and learning (pp. 3746). New York: Oxford University Press.

Hinrichs, J. V., Mewaldt, S. P., \& Redding, J. (1973). The Ranschberg effect: Repetition and guessing factors in short-term memory. Journal of Verbal Learning \& Verbal Behavior, 12, 64-75.

HinTZMAN, D. L. (1986). "Schema abstraction"' in a multiple-trace memory model. Psychological Review, 93, 411-428.
JAHNKE, J. C. (1969). Ourput interference and the Ranschberg effect. Journal of Verbal Learning \& Verbal Behavior, 8, 614-621.

JAKobson, R., FANT, G. M., \& HALle, M. (1951). Preliminaries to speech analysis. Cambridge, MA: M.I.T. Press.

JAMES, W. (1890). The principles of psychology. New York: Holt, Rinehart \& Winston.

Johnson, M. K., \& RAye, C. L. (1981). Reality monitoring. Psychological Review, 88, 67-85.

Kahneman, D. (1973). Attention and effort. Englewood Cliffs, NJ: Prentice-Hall.

Kahneman, D., \& Henik, A. (1981). Perceptual organization and attention. In M. Kubovy \& J. Pomerantz (Eds.), Perceptual organization (pp. 181-212). Hillsdale, NJ: Erlbaum.

Kahneman, D., Onuska, L., \&olman, R. E. (1968). Effects of grouping on the pupillary response in a short-term memory task. Quarterly Joumal of Experimental Psychology, 20, 309-311.

LEE, C. L., \& EsTES, W. K. (1977). Order and position in primary memory for letter strings. Journal of Verbal Learning \& Verbal Behavior, 16, 395-418.

LEE, C. L., \& EsTES, W. K. (1981). Item and order information in shortterm memory: Evidence for multilevel perturbation processes. Journal of Experimental Psychology: Learning, Memory, \& Cognition, 7, 149-169.

LEVY, B. A. (1971). The role of articulation in auditory and visual shortterm memory. Journal of Verbal Learning \& Verbal Behavior, 10, 123-132.

Lewandowsky, S., MURDock, B. B., JR. (1989). Memory for serial order. Psychological Review, 96, 25-57.

LuCE, R. D. (1963). Detection and recognition. In R. D. Luce, R. R Bush, \& E. Galanter (Eds.), Handbook of mathematical psychology (pp. 103-189). New York: Wiley.

Metcalfe, J., Glavanov, D., \& Murdock, M. (1981). Spatial and temporal processing in the auditory and visual modalities. Memory \& Cognition, 9, 351-359.

Morton, J. (1970). A functional model of memory. In D. A. Norman (Ed.), Models of human memory (pp. 203-260). New York: Academic Press.

MORTON, J. (1976). Two mechanisms in the stimulus suffix effect Memory \& Cognition, 4, 144-149.

Morton, J., Marcus, S. M., \& Ottley, P. (1981). The acoustic correlates of "speech-like": A use of the stimulus suffix effect. Joumal of Experimental Psychology: General, 110, 568-593.

MURDOCK, B. B., JR. (1966). Measurement of retention of interpolated activity in short-term memory. Joumal of Verbal Learning \& Verbal Behavior, 5, 469-472.

Murdock, B. B., JR. (1974). Human memory: Theory and data. Potomac, MD: Erlbaum.

MURDOCK, B. B., JR. (1983). A distributed memory model for serialorder information. Psychological Review, 90, 316-338.

MURDock, B. B., JR., \& W WLKER, K. D. (1969). Modality effects in free recall. Journal of Verbal Learning \& Verbal Behavior, 8, 665-676.

MURRAY, D. J. (1966). Vocalization-at-presentation and immediate recall, with varying recall methods. Quarterly Joumal of Experimental Psychology, 18, 9-18.

NAIRNE, J. S. (1988). A framework for interpreting recency effects in immediate serial recall. Memory \& Cognition, 16, 343-352.

NaIRNE, J. S., \& McNABB, W. K. (1985). More modality effects in the absence of sound. Journal of Experimental Psychology: Leaming, Memory, \& Cognition, 11, 596-604.

NairNe, J. S., \& Walters, V. L. (1983). Silent mouthing produces modality- and suffix-like effects. Journal of Verbal Learning \& Verbal Behavior, 22, 475-483.

NICKERSON, R. S. (1984). Retrieval inhibition from part-set cuing: A persisting enigma in memory research. Memory \& Cognition, 12 , 531-552.

NosoFsKY, R. M. (1986). Attention, similarity, and the identificationcategorization relationship. Journal of Experimental Psychology. General, 115, 39-57.

PenNey, C. G. (1985). Elimination of the suffix effect on preterminal list items with unpredictable list length: Evidence for a dual model 
of suffix effects. Journal of Experimental Psychology: Learning, Memory, \& Cognition, 11, 229-247.

PenNey, C. G. (1989). Modality effects and the structure of short-term verbal memory. Memory \& Cognition, 17, 398-422.

Peterson, L. R., Johnson, S. T. (1971). Some effects of minimizing articulation on short-term retention. Journal of Verbal Learning \& Verbal Behavior, 10, 346-354.

Peterson, L. R., \& Peterson, M. J. (1959). Short-term retention of individual items. Journal of Experimental Psychology, 58, 193-198.

RaAijmakers, J. G. W., \& Shiffrin, R. M. (1981). Search of associative memory. Psychological Review, 95, 93-134

RATCLIFF, R., \& MCKoon, G. (1988). A retrieval theory of priming in memory. Psychological Review, 95, 385-408.

Russo, J. E., \& WISHER, R. A. (1976). Reprocessing as a recognition cue. Memory \& Cognition, 4, 683-689.

RYAN, J. (1969). Grouping and short-term memory: Different means and patterns of groups. Quarterly Joumal of Experimental Psychology, 21, 137-147.

SCHWEICKERT, R., \& BoRUFF, B. (1986). Short-term memory capacity: Magic number or magic spell? Joumal of Experimental Psychology: Learning, Memory, \& Cognition, 12, 419-425.

Shand, M. A., \& Klima, E. S. (1981). Nonauditory suffix effects in congenitally deaf signers of American Sign Language. Journal of Experimental Psychology: Human Learning \& Memory, 7, 464-474.

SHEPARD, R. N. (1957). Stimulus and response generalization: A stochastic model relating generalization to psychological space. Psychometrika, 22, 325-345.

SHEPARD, R. N. (1961). Role of generalization in stimulus-response compatibility. Perceptual \& Motor Skills, 13, 59-62.

SHEPARD, R. N. (1987). Toward a universal law of generalization for psychological science. Science, 237, 1317-1323.

ShIfFRIN, R. M., \& CoOK, J. R. (1978). Short-term forgetting of item and order information. Joumal of Verbal Leaming \& Verbal Behavior, 17, 189-218.

Shulman, H. G. (1972). Semantic confusion errors in short-term memory. Joumal of Verbal Leaming \& Verbal Behavior, 11, 221- 227.

Watkins, M. J., PeynircioĞlu, Z. F., \& Brems, D. J. (1984). Pictorial rehearsal. Memory \& Cognition, 12, 553-557.

Watkins, M. J., Watkins, O. C., \& Crowder, R. G. (1974). The modality effect in free and serial recall as a function of phonological similarity. Journal of Verbal Learning \& Verbal Behavior, 11, 221-227.

WatKINS, O. C., \& WatKINS, M. J. (1975). Build-up of proactive in- hibition as a cue-overload effect. Journal of Experimental Psychology: Human Learning \& Memory, 1, 442-452.

Watkins, O. C., \& WaTKINS, M. J. (1980). The modality effect and echoic persistence. Joumal of Experimental Psychology: General, 109, 251-278.

WATKINS, O. C., \& WATKINS, M. J. (1982). Lateral inhibition and echoic memory: Some comments on Crowder's (1978) theory. Memory \& Cognition, 10, 279-286.

Waugh, N. C., \& Norman, D. A. (1965). Primary memory. Psychological Review, 72, 89-104.

WiCKeNS, D. D. (1972). Characteristics of word encoding. In A. W. Melton \& E. Martin (Eds.), Coding processes in human memory (pp. 191-215). Washington, DC: Winston.

Wickens, D. D., Born, D. G., \& Allen, C. K. (1963). Proactive inhibition and item similarity in short-term memory. Journal of Verbal Learning \& Verbal Behavior, 2, 440-445.

YNTEMA, D. B., \& Trask, F. P. (1963). Recall as a search process. Journal of Verbal Learning \& Verbal Behavior, 2, 65-74.

\section{NOTES}

1. Alternatively, one might assume that features are not erased, but rather "swap" positions with interfering items in a manner described by the Estes perturbation model (Estes, 1972). One of the unique aspects of the perturbation approach is the probability that a feature may swap back to its original position, producing apparent recovery in some instances. Estes (1972) was interested in using feature swapping as a mechanism for explaining loss in item information, but that aspect of the model has not been explored in any detail.

2. First, rehearsal is seen as interfering with the active representations of list items in primary memory. Rehearsal may still have a net positive effect in long-term memory by increasing the strength of the list vectors in secondary memory-perhaps by simply increasing the sheer number of list representations in secondary memory. Second, data from a study by M. J. Watkins, Peynircioğlu, and Brems (1984) indicate that it might be possible to rehearse modality-dependent features under some task demands.

3. Since overwritten features were assigned a value of zero, they were always mismatched with their comparable feature positions in the secondary memory search set vectors.

(Manuscript received June 28, 1989; revision accepted for publication October 30, 1989.) 